\title{
Long-Range Regulation of Key Sex Determination Genes
}

\author{
Roberta Migale Michelle Neumann Robin Lovell-Badge \\ The Francis Crick Institute, London, UK
}

\section{Keywords}

Enhancers · FOXL2 · Gonads · Sex determination · SOX9

\begin{abstract}
The development of sexually dimorphic gonads is a unique process that starts with the specification of the bipotential genital ridges and culminates with the development of fully differentiated ovaries and testes in females and males, respectively. Research on sex determination has been mostly focused on the identification of sex determination genes, the majority of which encode for proteins and specifically transcription factors such as SOX9 in the testes and FOXL2 in the ovaries. Our understanding of which factors may be critical for sex determination have benefited from the study of human disorders of sex development (DSD) and animal models, such as the mouse and the goat, as these often replicate the same phenotypes observed in humans when mutations or chromosomic rearrangements arise in proteincoding genes. Despite the advances made so far in explaining the role of key factors such as SRY, SOX9, and FOXL2 and the genes they control, what may regulate these factors upstream is not entirely understood, often resulting in the inability to correctly diagnose DSD patients. The role of noncoding DNA, which represents $98 \%$ of the human genome, in sex determination has only recently begun to be fully appreciated. In this review, we summarize the current knowledge on the long-range regulation of 2 important sex deter-
\end{abstract}

(c) 2021 S. Karger AG, Basel

www.karger.com/sxd mination genes, SOX9 and FOXL2, and discuss the challenges that lie ahead and the many avenues of research yet to be explored in the sex determination field.

(c) 2021 S. Karger AG, Basel

\section{Sex Determination in Mammals}

The development of sexually distinct reproductive organs, notably testes and ovaries in males and females, respectively, is a time-dependent mechanism of utmost importance for successful production of gametes and survival of a species. The mammalian gonads derive from a pair of bipotential genital ridges that can develop as either ovaries or testes depending on which genetic program is activated (Fig. 1). In mammalian primary sex determination, there is no "default state". The formation of ovaries and testes are both active, gene-directed processes and have to be maintained throughout life to ensure Sertoli and granulosa cell identity.

Our current knowledge of mammalian sex determination is based on insights from individuals with disorders of sex development (DSD), which comprises a group of congenital conditions associated with atypical development of internal and external genitalia with an incidence between 0.2 and $0.5 \%$, making it the most frequent birth defect [Delot and Vilain, 2021], and from mouse models [Eggers and Sinclair, 2012]. The first sex determination 


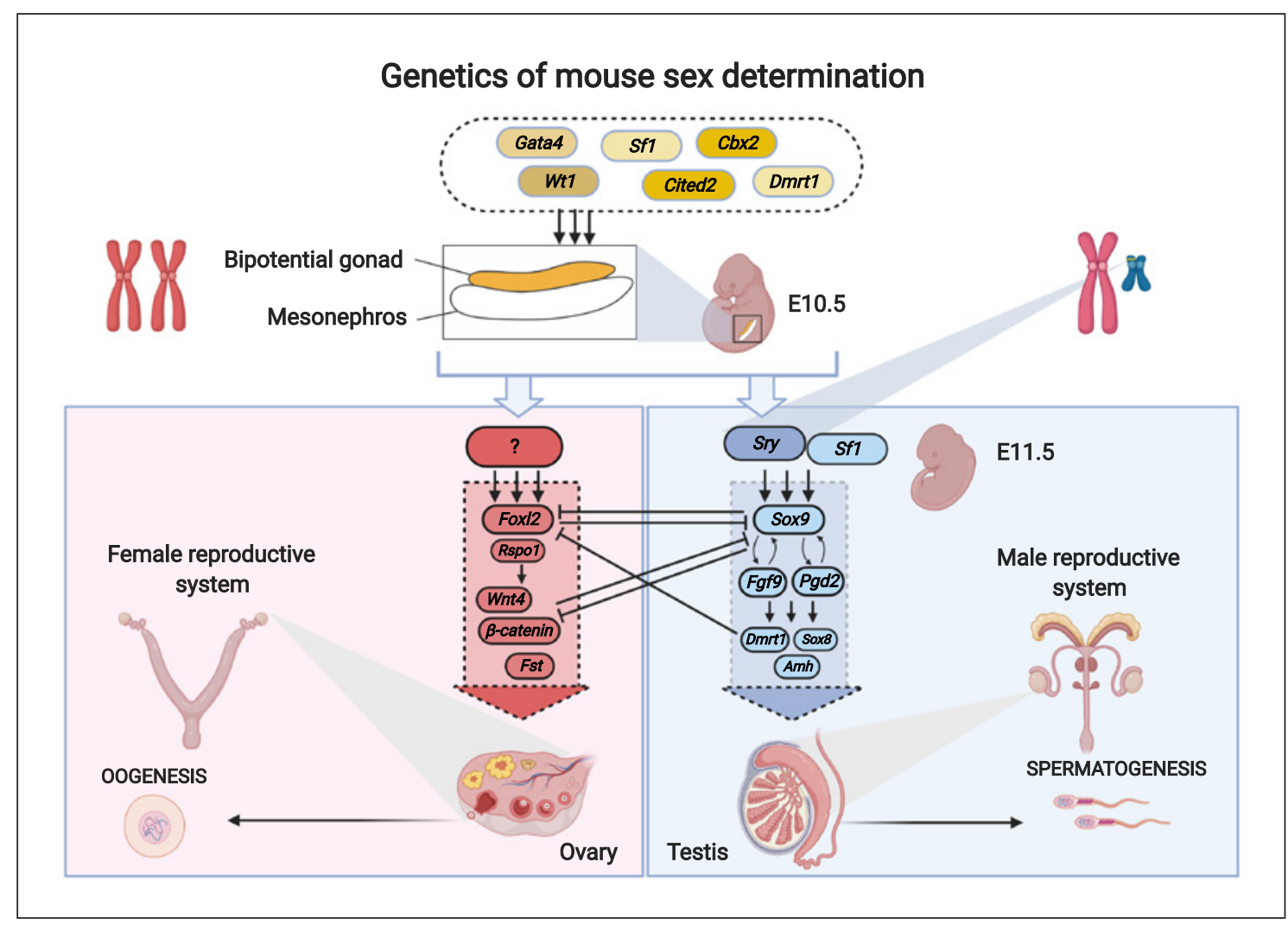

Fig. 1. Genetics of mouse sex determination and gonadal development. The formation of ovaries and testes are both active, gene-directed processes. Mouse gonads are initially specified as bipotential genital ridges around E10.5 of gestation and then develop as either ovaries (left) or testes (right) depending on which genes are activated. Mutual antagonism (flathead lines) and activation (arrowhead lines) between genes are depicted. Created with BioRender.com.

gene, SRY (sex-determining region of the Y chromosome), was identified in humans within a $35-\mathrm{kb}$ region unique to the $\mathrm{Y}$ chromosome that had been found in $4 \mathrm{XX}$ individuals exhibiting male characteristics [Sinclair et al., 1990]. Subsequently, point mutations were discovered in $S R Y$ in XY female individuals, suggesting a critical role for this factor in testis development [Berta et al., 1990]. The use of mouse models was instrumental both to discovering the gene and in understanding its role in mammalian sex determination. Sry was isolated in the mouse in 1990 and 1 year later shown to be sufficient to induce male development when ectopically expressed in XX females [Gubbay et al., 1990; Koopman et al., 1991]. Sry encodes for a transcription factor whose main role is to upregulate Sox9 (SRY-box containing gene 9) expression, which in turn triggers the male-specific differentiation of the supporting cell precursor lineage (the Sertoli cells) by working together with several additional transcription factors, including GATA4, WT1, DMRT1, and SF1 [Lovell-Badge and Robertson, 1990; Koopman et al., 1991; Bullejos and Koopman, 2001; Buganim et al., 2012]. Differentiation of Sertoli cells is critical for testis development as these cells will in turn direct the differentiation of other somatic cell lineages of the testis (namely Leydig and peritubular myoid cells). In the absence of Sry in XX embryos, the WNT4/RSPO1/CTNNB1/FOXL2 pathways are activated, leading to the female specific differentiation of the supporting cell lineage (the granulosa cells) [Vainio et al., 1999; Jeays-Ward et al., 2003; Parma et al., 2006; Maatouk et al., 2008].

The process of sex determination, and the establishment and the maintenance of gonadal sex identity are strongly dependent on a mutual antagonism between male and female pathways.

Mouse genetic studies demonstrated that the stability of these pathways relies on the activation and mainte- 
nance of mutually antagonistic gene networks. In the female gonad, loss of Foxl2 leads to Sox9 activation and female-to-male transdifferentiation [Uhlenhaut et al., 2009]. Conversely, in the male gonad, loss of Dmrt1 or loss of both Sox9 and Sox 8 triggers the transdifferentiation of Sertoli cells to granulosa-like cells [Matson et al., 2011; Barrionuevo et al., 2016]. More recently, work by the Zarkower lab has revealed that DMRT1 actually cooperates with SOX9 during female-to-male reprogramming by acting as pioneer factor, opening up the chromatin and thus allowing SOX9 binding to accessible genomic regions [Lindeman et al., 2021]. This study importantly highlighted how DMRT1 and SOX9 are both required for the regulation of the many sex-biased genes that control transdifferentiation. Mouse models have also represented valuable tools to explore the gene-dosage effects on gonadal development, for example a study by Correa et al. [2012] has shown that Wt1, Sf1, and Wnt4 genes are dosage-sensitive in a background-dependent way, similarly to humans [Swain et al., 1998; Correa et al., 2012].

The need for finely tuned gene expression in gonadal development is evident from studies of DSD cases, revealing the importance of gene dosage for proper sex determination in human [Bardoni et al., 1994; Foster et al., 1994; Wagner et al., 1994; Jordan et al., 2001].

Based on recent studies, copy number variants (CNV) affecting coding sequences or regulatory elements, as well as single nucleotide variants (SNV) in at least 75 genes including $S R Y, S O X 9, W T 1, W N T 4$ are known to cause DSD [Parivesh et al., 2019; Delot and Vilain, 2021]. However, only $43 \%$ of $46, \mathrm{XY}$ and $17 \%$ of 46 ,XX DSD individuals will receive a genetic diagnosis even with the use of massively parallel sequencing (MPS) targeted to both known diagnostic genes and additional candidate genes [Eggers et al., 2016]. These rates can be lower in a purely clinical setting where access to high-throughput techniques may not be readily available and/or accessible from the national health system [Eggers et al., 2016]. Given that most of the genes important for sex development required a controlled spatiotemporal expression, it is likely that a part of the undiagnosed cases of DSD may be caused by disruption of their regulatory elements [Baetens et al., 2017]. Typically, the genetic tools available to screen DSD individuals do not survey the non-coding portion of the genome, thus leaving a high percentage of individuals without a diagnosis.

The most extensively studied regulatory region linked with DSD is the gene desert upstream of SOX9 [Wagner et al., 1994; Benko et al., 2011; Kim et al., 2015; Baetens et al., 2017]. Given the critical role of SOX9 in sex determination, an increasing number of studies have started to investigate how its expression may be regulated. Recent studies have revealed a number of regulatory elements residing within the gene desert upstream of the SOX9 promoter some of which are important for both mouse and human testis development [Sekido and Lovell-Badge, 2008; Gonen et al., 2017, 2018; Croft et al., 2018a; Ogawa et al., 2018].

In this review, we will discuss the long-range regulation of SOX9 and its role in gonadal sex determination and development. Although specific enhancers regulating FOXL2 expression in the ovary have not yet been identified, we will provide a summary of the current knowledge available on FOXL2 gene regulation generated from the study of blepharophimosis/ptosis/epicanthus inversus syndrome (BPES) patients, and from 2 animal models: the Polled Intersex Syndrome (PIS) goat [Pailhoux et al., 2001] and the Foxl2 ${ }^{P B / P B}$ mouse line (PB: piggyBac) [Shi et al., 2014].

\section{Role of SOX9 in Testis Development}

SOX9 is a well-conserved transcription factor regulating the differentiation of cells from all 3 germ layers into a variety of tissues and organs, with a prominent role in establishing and maintaining stem and progenitor cell pools, but also in the differentiation of cartilage and Sertoli cells [Jo et al., 2014]. It is a member of the SRY-related HMG box (SOX) family of transcription factors which are characterized by a high-mobility-group (HMG) domain that can bind DNA at the consensus motif A/TA/ TCAAA/TG by forming a L-shaped complex in the minor groove of DNA [Mertin et al., 1999]. SOX proteins can be divided in 10 sub-families, A-J, based on homology within their HMG domain and other structural motifs [Bowles et al., 2000; Schepers et al., 2002]. Together with SOX8 and SOX10, SOX9 belongs to the SOXE subfamily which is conserved in mammals and most vertebrates and share homology beyond the HMG domain, including a self-dimerization domain at the $\mathrm{N}$-terminus and a bipartite transactivation domain in the center (TAM) which synergize with a transactivation domain located at their C-terminal side (TAC). Additionally, SOX9 carries a unique PQA-rich region located between TAM and TAC which may contribute to its stability and transactivation [Haseeb and Lefebvre, 2019].

SOXE genes are often overlapping in their expression pattern and function, encoding for factors that act togeth- 
er, redundantly or exclusively, in several developmental processes such as chondrogenesis [Bi et al., 1999; Akiyama et al., 2002], melanogenesis [Harris et al., 2010], neuronal and glia differentiation, and sex determination [Weider and Wegner, 2017]. Sox9 is a direct target of SRY and its expression is both required and sufficient to direct the bipotential gonad towards testis development as shown by experimental induction of ectopic Sox 9 expression in XX mice [Vidal et al., 2001; Qin and Bishop, 2005; Barrionuevo et al., 2006]. Sox9 is expressed at basal levels in both XX and XY mouse gonads before sex determination [Morais da Silva et al., 1996]. The transient expression of SRY in the supporting cell precursors between E10.5 and E12.5 of XY gonads leads to Sox9 upregulation, Sertoli cell differentiation, and testis development [Kent et al., 1996; Sekido et al., 2004; Wilhelm et al., 2005; Hiramatsu et al., 2009]. SOX9 needs to reach a threshold level to repress Sry, to maintain its own expression through interaction with SF1, FGF9, and PGD2 and to propagate the male cell fate decision to surrounding cells through paracrine signals [Kim et al., 2006; Wilhelm et al., 2007; Sekido and Lovell-Badge, 2008; Moniot et al., 2009].

As SOX9 plays critical roles in development of many tissues, mice carrying homozygous mutations die around E11.5, the time of sex determination, making it impossible to test the effects of complete Sox9 loss in the mutants. Chaboissier et al. [2004] were able to circumvent this problem by keeping genital ridges alive in ex vivo culture for an extra 3 days, enough time to demonstrate that genital ridges from homozygous mice failed to form testis cords and did not express any of the male-specific markers found in a functional testis.

Studies performed on a conditional Sox 9 mouse model, where Sox 9 was specifically deleted from E10, before sex determination, in $S f 1$-expressing gonadal cells, further confirmed its essential role in Sertoli cell differentiation and seminiferous tubule formation as all XY mice with Sox 9 conditional inactivation in the gonads showed sex reversal [Akiyama et al., 2002; Chaboissier et al., 2004; Barrionuevo et al., 2006]. In contrast, conditional deletion of Sox 9 at around E14, after sex determination, using an $A m h^{C r e}$ line did not affect embryonic testes development. The mutant mice were fertile for around 5 months after which they started to show dysfunctional spermatogenesis [Barrionuevo et al., 2009].

This was likely due to the redundant role played by SOX8 and supported by studies on mice double knockout for Sox8 and Sox9 [Chaboissier et al., 2004]. Sox8 is indeed activated downstream of Sox 9 with which it shares $67 \%$ of homology [Schepers et al., 2000].

Enhancers and Sex Determination
Homozygous Sox8 XY knockout mice developed normal testes [Sock et al., 2001], whilst tissue specific knockout of Sox9 induced defects in testis cords formation to different degrees [Chaboissier et al., 2004]. This abnormal phenotype was further accentuated in mice where Sox9 was conditionally deleted (Hom or Het) on a Sox8 null background, with double knockout mice often showing complete absence of sex cord formation, supporting an interplay between these 2 factors in proper testis development [Chaboissier et al., 2004].

The conserved role played by SOX9 in sex determination and testis differentiation was evident from earlier studies where its expression was found to be sexually dimorphic in mouse as well as many other vertebrates which do not possess an SRY gene [Morais da Silva et al., 1996]. In chicken, SOX9 expression follows the expression of DMRT1, a factor which was recently identified as the sex determination switch in chickens [Ioannidis et al., 2021]. Ectopic expression of DMRT1 in ZW females can upregulate SOX9 inducing masculinization of the gonads, thus supporting a role for SOX9 in testis differentiation in this organism [Lambeth et al., 2014]. In sea turtles, which have evolved a temperature-dependent sex determination system instead of a genetic one, SOX9 is critical for testis differentiation [Moreno-Mendoza et al., 1999], and in zebrafish SOX9 was found to control juvenile ovary-to-testis transformation [Sun et al., 2013].

These pivotal studies and others have demonstrated a conserved role for SOX9 in testis development. The majority of the work that followed has been directed towards identifying which targets SOX9 is regulating and how SOX9 may be regulated itself. A ChIP-on-chip study performed on mouse gonadal cells at the time of sex determination and investigating the target genes of SRY and SOX9 found about 3,000 and 1,900 targets, respectively, of which about 900 were shared [Li et al., 2014]. These shared genes were mostly involved in Sertoli cell adhesion, tight junction dynamics, and actin cytoskeleton signaling, suggesting that SRY and SOX9 may cooperate in establishing early testis cord formation, with SOX9 possibly taking over the role after Sry has been switched off, at least in the mouse. A later study [Rahmoun et al., 2017], applying a more sensitive technique (ChIP-Seq), to bovine and mouse fetal testes identified a greater number of SOX9 targets in Sertoli cells [Rahmoun et al., 2017]. This study identified about 4,200 genes conserved in both organisms that are bound by SOX9 at equivalent stages of fetal testis development including most of the already known genes critical for sex determination. The integration of these ChIP-Seq data with RNA sequencing data 
derived from the comparison of XY and XX somatic gonadal cells in wildtype mice, as well as in a SOX9 knockout model, indicated that SOX9 may work not only as activator of testis-specific genes but also as a repressor of ovaryspecific genes [Jameson et al., 2012; Rahmoun et al., 2017].

Not many studies have tackled the question of how SOX9 regulatory regions may be conserved amongst different species. Recently, a comparative analysis of ChIPSeq and RNA-Seq data from mouse and chicken limb buds and testes has started to provide some information on the conservation of SOX9 binding sites and target genes [Yamashita et al., 2019]. While many similarities were observed between chicken and mouse in terms of SOX9 genomic occupancy in limb bud tissue, testicular cells revealed a significant number of targets not being shared between the 2 organisms. This points towards a cell-specific binding of SOX9 in chicken and mouse which could potentially hint to a differential SOX9 gene regulation upstream as SOX9 may interact with different partners in each cell type which would direct its binding to different genomic regions.

These studies have revealed the broad range of SOX9 targets genes and the mechanisms underlying SOX9-mediated regulation of testis development, however, relatively few studies have been focused on understanding how SOX9 expression itself may be regulated. Evidence from the study of DSD as well as mouse models have been essential to learn more about the fascinating mechanism behind the gene regulation of such an important developmental gene.

\section{Chromosomal Rearrangements of SOX9 Regulatory Region Cause DSD}

The SOX9 gene was first discovered by studying patients with campomelic dysplasia (CD; OMIM 114290) [Foster et al., 1994; Kwok et al., 1995]. CD is an haploinsufficiency disorder characterized by defects in the development of the skeletal system due to defective chondrogenesis and a high incidence of male-to-female sex reversal, which is seen in two-thirds of XY patients [Foster et al., 1994]. The degree of sex reversal varies with the most common scenario being the birth of phenotypically normal XY females with dysgenic ovaries [Foster et al., 1994]. Genetic analyses of CD patients carrying a single mutation in one of their SOX9 alleles provided the first link between the gene and sex determination as these patients could not develop functional testes. Many of the genetic defects found in these patients were located within the coding sequence of SOX9, however, additional studies have revealed mutations beyond the SOX 9 coding region, providing the first indication that important regulatory sequences must be located a long distance upstream of its open reading frame [Wagner et al., 1994; Wunderle et al., 1998]. The considerable size of the SOX9 regulatory region became more evident with the isolation of the PierreRobin sequence (PRS; OMIM 261800). PRS patients display craniofacial anomalies caused by microdeletions or translocations breakpoints identified more than $1 \mathrm{MB}$ upstream of SOX9 [Jakobsen et al., 2007]. A recent study identified the 2 specific enhancer clusters responsible for this phenotype as located 1.25 and $1.45 \mathrm{Mb}$ upstream of SOX9, which are essential for its regulation in cranial neural crest development [Long et al., 2020]. Additional SOX9 regulatory sequences were also identified downstream of the gene [Velagaleti et al., 2005; Benko et al., 2009; Kim et al., 2015]. Duplications of the SOX9 gene have also been found in cases of XX male sex reversal, indicating that ectopic expression of SOX9 in chromosomally female individuals can trigger testis development in the absence of $S R Y$ [Huang et al., 1999]. Altogether, these clinical data provided the first evidence that the proper regulation and expression of SOX9 is necessary for normal testis development in the human and pointed towards the existence of long-range enhancers important for its expression.

\section{Two Mouse Models Initially Revealed a Complex Sox9 Regulatory Region}

In the mouse, the first evidence suggesting the presence of important regulatory regions upstream of Sox9 came from the Odd Sex (Ods) model [Bishop et al., 2000]. The Ods mutation emerged in a transgenic line carrying a Dct-tyrosinase minigene used to rescue the albinism phenotype. The construct integrated $0.98 \mathrm{Mb}$ upstream of Sox9 and was associated with a 134-kb deletion in this region. XX mice heterozygous for this mutation exhibited female-to-male sex reversal due to ectopic activation of Sox9 in the gonads and developed as sterile males. A follow-up study looking at the $134-\mathrm{kb}$ deletion clarified that this phenotype was due to the interaction of the Dct promoter with gonadal enhancers, since the 134-kb deletion alone did not result in sex reversal [Qin et al., 2004]. Importantly, this study demonstrated that the Ods mutation is capable of acting over a distance of $1 \mathrm{Mb}$ thus inducing ectopic expression of Sox9 in XX mice. 
The C57BL/6J-YPOS (B6- $\mathrm{Y}^{\mathrm{POS}}$ ) mouse model has been instrumental for the identification of the first genomic regions that may regulate Sox9. The strain's autosomes and $\mathrm{X}$ chromosome come from the inbred Mus musculus C57BL/6J strain, whilst the $\mathrm{Y}$ chromosome is from the wild-derived M. domesticus poschiavinus (POS) sub-strain [Bullejos and Koopman, 2005; Arboleda et al., 2014]. B6- $Y^{\mathrm{POS}} \mathrm{XY}$ mice present a delay in Sry expression, often resulting in complete XY female sex reversal. Through genetic back crossing it was established that a $55-\mathrm{Mb}$ congenic region on chromosome 11, later refined to $1.62-\mathrm{Mb}$, conferred $80 \%$ protection from the $\mathrm{B} 6-\mathrm{Y}^{\mathrm{POS}}$ sex reversal phenotype. This region mapped within the Sox9 promoter and induced its expression, thus rescuing the $\mathrm{B} 6-\mathrm{Y}^{\mathrm{POS}}$ mice from sex reversal. This region of 1.62$\mathrm{Mb}$, named region 110, spans most of the upstream Sox 9 regulatory region that we now know contains important Sox9 enhancers regulating testis-specific expression.

\section{Discovery of Gonadal-Specific Enhancers Regulating SOX9}

Enhancers are responsible for driving tissue-specific expression of a particular gene. Whilst mutations in the coding region of a gene are likely to affect all tissues where a protein is expressed, mutations within enhancers may only affect a specific tissue in which that enhancer is active. The evidence that over two-thirds of CD patients showed male-to-female sex reversal and carried chromosomal rearrangements upstream of SOX 9 prompted research aimed to investigate the potential involvement of critical elements within this gene desert in testis development [Foster et al., 1994; Wagner et al., 1994]. The first to tackle this challenge was a study by Sekido and LovellBadge [2008] that generated a transgenic mouse using a bacterial artificial chromosome (BAC) clone carrying a lac $Z$ reporter gene driven by a basic promoter and a sequence between -70 and $+50 \mathrm{~kb}$ of Sox9. Through serial deletion of this BAC construct, a 3.2-kb, male-specific enhancer named TES (testis-specific enhancer of Sox9) was identified as driving lacZ expression specifically in Sertoli cells, similar to endogenous Sox9. TES was further divided into 3 fragments, namely EC1, EC2, and EC3, that were tested for gonadal expression. It was found that the central region EC2, containing a conserved sequence spanning $1.4 \mathrm{~kb}$ rich in SF1, SRY, and SOX9 binding sites, maintained enhancer activity in the mouse gonad and was named TESCO (TES core). The generation of transgenic mice carrying SRY and SF1 mutated binding sites, showed that only the simultaneous mutation of these binding sites abolished enhancer activity, confirming that SRY and SF1 mutual binding onto TESCO is essential [Sekido and Lovell-Badge, 2008].

Whilst this work unraveled the presence of a testisspecific enhancer of Sox9, its role in the developing testis had not been fully explored until a more recent study where TES and TESCO were deleted in the mouse using CRISPR-Cas9 technology [Gonen et al., 2017]. Quite surprisingly, when either TESCO or the bigger TES were deleted at both Sox9 alleles, no sex reversal was observed. Mutant XY mice had normal testes and were fertile in a mixed genetic background strain as well as in C57BL/6J, which is notably more sensitive to sex reversal [Eicher et al., 1996; Munger et al., 2009]. Gene expression analysis of Sertoli cell markers in TES and TESCO mutants revealed that Sox9 mRNA expression was reduced in E13.5 testes, showing 44 and $62 \%$ of wildtype levels, respectively, but no significant increase in female granulosa cell markers was observed. SOX9 protein expression was also unaffected in mutants, clearly demonstrating that TES/ TESCO enhancers are not critical for proper testis development and that a $44 \%$ level of Sox9 gene expression is sufficient to allow testis differentiation in the mouse. A compound line carrying the TES deletion and a conditional null allele of Sox 9 showed further reduction of Sox9 mRNA levels to about $25 \%$ compared to wildtype and resulted in the development of ovotestes [Gonen et al., 2017]. These findings demonstrated that the Sox 9 threshold level of expression necessary to ensure proper testis development in the mouse is $25 \%$ of wildtype level. This is about half the levels necessary in the human, where heterozygosity for Sox9 null mutations leads to XY male-tofemale sex reversal in $70 \%$ of CD cases.

It was initially hypothesized that TES may also act as hub for binding of ovary-specific factors which could repress Sox9 in the female context. Although binding sites for FOXL2, TCF (a $\beta$-catenin cofactor), and DAX1 were found in TES [Uhlenhaut et al., 2009; Bernard et al., 2012; Ludbrook et al., 2012], Gonen et al. [2017] showed that deletion of either TES or TESCO in XX female mice did not cause the de-repression of male-specific genes and female mutants were fertile suggesting that additional enhancers critical for Sox9 gene repression may reside somewhere outside TES.

Since no DSD patients have been identified so far with mutations or rearrangements within TESCO, it also seemed likely that this region was not critical for SOX9 expression in humans [Georg et al., 2010]. Copy number variation $(\mathrm{CNV})$ assays and multiplex ligation-depen- 
dent probe amplification (MLPA) are 2 widely used approaches to survey for genome-wide or for a targeted panel of known CNVs, respectively [Schouten et al., 2002]. Whilst these techniques have the potential to scan any part of the genome, most of the large-scale studies conducted on DSD patients have been focused on CNVs within the genes' coding region as reviewed in Croft et al. [2018b]. Of the few studies focused on the regulatory regions, the SOX9 locus has been the most well characterized. CNV array studies have identified 2 regulatory regions within the $2-\mathrm{Mb}$ region upstream of $\mathrm{SOX} 9$, whose deletion/duplication caused DSD. The first region, named RevSex, is located 516-584 kb upstream of SOX9. 46,XX individuals with RevSex duplication display female-tomale sex reversal, whereas 46,XY individuals with RevSex deletion have male-to-female sex reversal and gonadal dysgenesis [Benko et al., 2011; Cox et al., 2011; Xiao et al., 2013; Kim et al., 2015]. Recently, the analysis of new DSD patients has allowed to further refine the minimal RevSex region to a $40-\mathrm{kb}$ fragment located $600 \mathrm{~kb}$ upstream of SOX9 containing evolutionarily conserved elements and then to a 24-kb region thought to likely contain a SOX9 critical enhancer [Hyon et al., 2015; Ohnesorg et al., 2017]. Another region named XYSR was identified 607.1$639.6 \mathrm{~kb}$ upstream of SOX9, whose deletion caused XY male-to-female sex reversal suggesting that also this region may contain another long-range SOX 9 enhancer [Kim et al., 2015]. Altogether, studies from mouse models and clinical data on DSD patients contributed to narrow down the search for a critical long-range enhancer of SOX9 as discussed below.

\section{A Single Enhancer Is Critical for SOX9 Expression in Sertoli Cells}

The first experimental proof that there was a critical enhancer for Sox 9 regulation in sex determination came from the work by Gonen et al. [2018]. Genome-wide analyses of chromatin accessibility (by ATAC-Seq) coupled with H3K27ac ChIP-Seq were used to systematically scan for enhancers potentially involved in regulating Sox 9 ex-

Fig. 2. Map of gonadal Sox9 enhances. a Upper panel, overview of genomic location of Sox9 enhancers in the mouse, based on data from Gonen et al. [2018] (mm10). Lower panel, IGV tracks of relevant enhancers showing ATAC-Seq and ChIP-Seq analyses as performed by Garcia-Moreno et al. [2019] and downloaded from the Gene Expression Omnibus database, accession number GSE118755 [Garcia-Moreno et al., 2019]. Data were re-aligned against mm10 pression [Maatouk et al., 2017; Garcia-Moreno et al., 2019]. Accessible regions in Sertoli and granulosa cells of the mouse embryonic gonads were compared at E10.5, before sex determination, and at E13.5, after the commitment to the male or female cell fate. Thirty-three potential enhancers were identified, 16 of which were then screened in vivo by a transgenic assay (Fig. 2a) [Gonen et al., 2018]. Reporter lines carrying a $L a c Z$ gene under the control of each enhancer, upstream of a $H s p 68$ minimal promoter, were used to check enhancer activity in the embryonic gonads of XX and XY embryos. Indeed, 2 enhancers showed strong activation in the embryonic testes (Enh13 and Enh14), whilst one (Enh8) was active in embryonic ovaries. CRISPR-Cas9 was used to delete each of the testis-specific enhancers and generate stable transgenic mouse lines. Whilst Enh14 deletion did not cause any noticeable phenotype, either morphologically or molecularly, homozygous deletion of Enh13 led to XY sex reversal [Gonen et al., 2018]. Sex-reversed ovaries showed expression of the ovarian markers FOXL2 and loss of SOX9 at both E13.5 and 6 weeks postnatally. External genitalia of $\mathrm{XY}$ Enh13 $3^{-/-}$were identical to XX wildtype, showing complete sex reversal with development of secondary sexual characteristics entirely matching the gonadal identity. This remarkable phenotype was robust as it was replicated in both the sex reversal-sensitive C57BL/6J strain as well as in the C57BL/6J x CBA mixed background. Quantitative RT-PCR analyses revealed that Sox9 mRNA levels in XY Enh13 ${ }^{-/-}$genital ridges at E11.5 were about $20 \%$ of those found in a wildtype male, well below the levels needed to ensure proper testis development, as previously shown [Gonen et al., 2017], similar to those seen in normal XX control gonads. Interestingly, the simultaneous deletion of TES and Enh13 did not show an additive effect on Sox9 mRNA levels nor affected the sex-reversed phenotype, suggesting that Enh13 is the critical Sox9 enhancer at least at very early stages of male sex determination.

Sry expression is known to persist when testis differentiation is impaired since SOX9 is in turn involved in suppressing Sry expression [Lee and Taketo, 1994]. In support of the idea that Enh13 may be more important

genome. b RSAT analysis [van Helden, 2003] of 3 Sox9 enhancers for putative binding sites of transcription factors involved in sex determination and maintenance. Matrix-scan (full options) algorithm was used, $p$ value set to $1 \mathrm{e}-3$. TF matrix profiles were downloaded from JASPAR database in the TRANSFAC format (http:// jaspar.genereg.net/tools/) and analyzed in RSAT. m, mouse; h, human. Coordinates are relative to the mouse genome ( $\mathrm{mm} 10)$.

(For figure see next page.) 


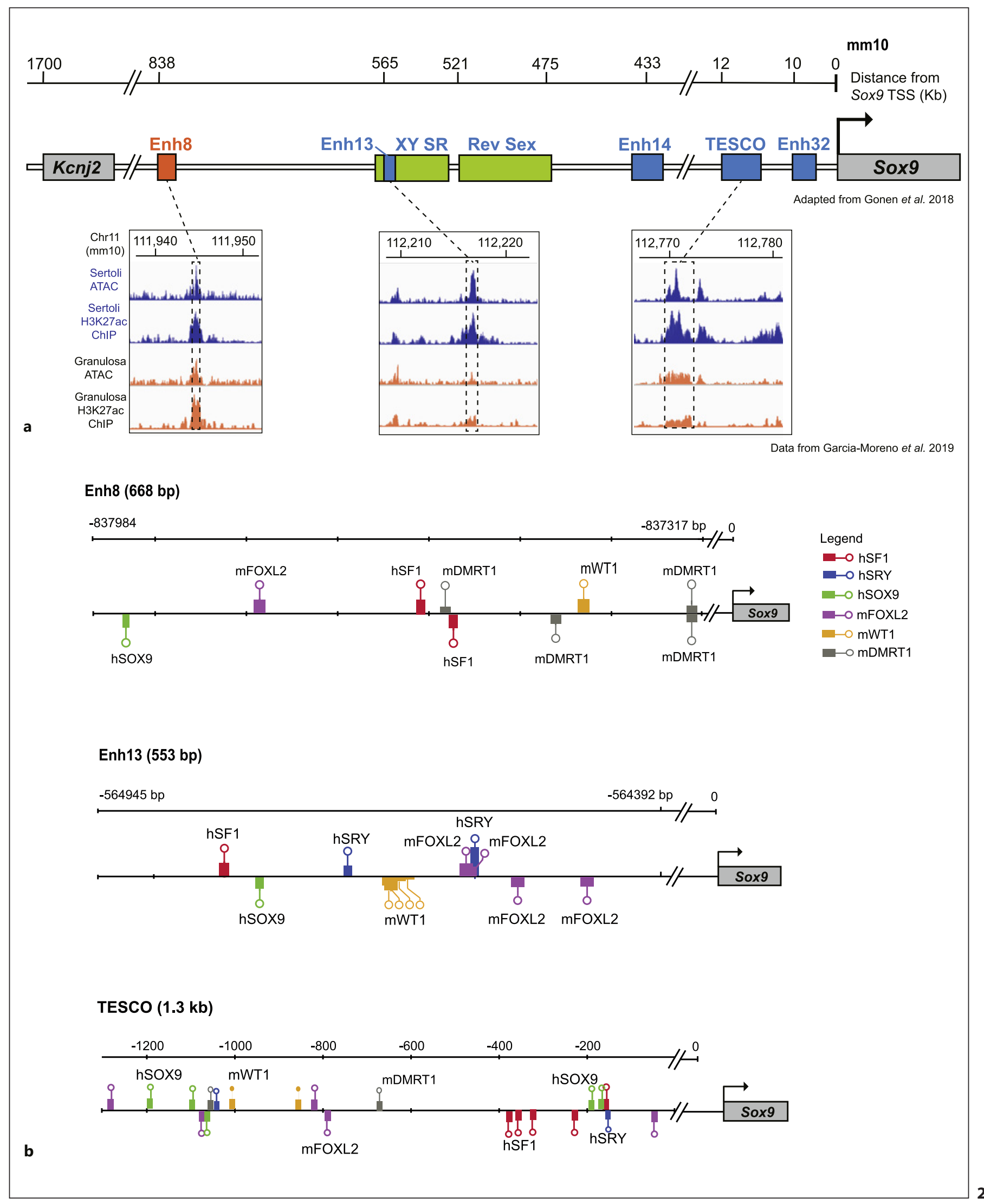

Enhancers and Sex Determination 
than TES for the initial Sox9 activation in XY normal testes, Sry mRNA expression was higher at E11.5 in both XY Enh $13^{+/-}$and XY Enh $13^{-/}$gonads compared to wildtype, whilst its levels did not change when TES was deleted. Additionally, Enh13 seemed also important for regulating the low levels of Sox9 mRNA normally observed in both sexes at E11.5, as its expression was lower by $30-50 \%$ in $\mathrm{XX}$ Enh $13^{-/-}$gonads compared to XX wildtype controls. This mouse model is the first and so far the only one demonstrating a role in sex determination for a single noncoding element, and it also further proves the absolutely critical role played by Sox9 in testis development. Remarkably, Enh13 is extremely well conserved across a wide range of mammals, including human, and contains several binding sites for transcription factors with an established role in sex determination such as SRY, SOX9, WT1, and SF1 (Fig. 2b). It shares high similarity to a fragment located within the $5^{\prime}$ portion of the XYSR region, strongly suggesting that Enh13 may play a critical role in proper SOX9 expression also in human.

Confirmation came from the study of a group of 44 DSD patients by Croft et al. [2018a]. Two 46,XX patients lacking $S R Y$ with testicular/ovotesticular DSD were carriers of a duplications of $23.9 \mathrm{~kb}$ and $24.2 \mathrm{~kb}$, respectively, mapping to the $2-\mathrm{Mb}$ regulatory region of SOX9. As shown by CGH-array, these duplications overlapped with each other as well as with XYSR for about $5.2 \mathrm{~kb}$ [Kim et al., 2015].

Functional in vitro assays were used to test enhancer activity in different cell lines (COS7, TM3, TM4, and HEK293 ) [Croft et al., 2018a]. In these assays, 5 overlapping fragments derived from the $5.2-\mathrm{kb}$ minimal region were co-transfected with SF1 and SOX9. Luciferase activity showed that the most active enhancer was a 1,514-bp fragment, which was named eSR-A, containing a binding site for SOX9/SRY and 2 for SF1. Mutations of the SOX9/ SRY site and 1 of the 2 SF1 sites, separately or together, impaired enhancer activity by about $78 \%$. Co-transfection with FOXL2, known to repress SOX9 in vivo [Uda et al., 2004], reduced enhancer activity by half. Comparison of the sequences of human eSR-A and mouse Enh13 showed that the 2 enhancers shared $80 \%$ sequence conservation. ChIP-qPCR assay in the mouse demonstrated that Enh13 is bound by SRY at E11.5 and by SOX9 at E13.5, suggesting that Enh13 may be first playing a role in the early sex determination decision through SRY binding and then in the commitment and maintenance of the male cell fate by SOX9 binding [Gonen et al., 2018]. Interestingly, Croft et al.[2018a] reported that co-transfection of eSR-A with SRY and SF1 did not lead to en- hancer activation, whilst co-transfection with SOX9 and SF1 did, suggesting that at least in human in an in vitro context, SOX9/SF1 and not SRY may be the critical factors binding to eSR-A. Alternatively, since human SRY is known to have weak activation properties [Zhao et al., 2014], it is also possible that in this experimental setting critical cofactors may be lacking thus not allowing enhancer activation.

Additionally, luciferase assays were used to test the activity of the different combinations of enhancers (eSR$\mathrm{A} / \mathrm{B}$ and eALDI) and showed that a greater response was achieved when all 3 enhancers were combined. All this evidence combined with the fact that duplication of these enhancers leads to sex reversal in 46,XX DSD patients lacking $S R Y$ suggests that an additional copy of a SOX9/ $S F 1$-specific enhancer in human may be enough to induce the recruitment of sufficient SF1 and SOX9 (perhaps through facilitating chromatin looping) present in XX fetal gonads at basal levels onto the SOX9 regulatory region, thus starting the male pathway despite the absence of SRY.

All these results demonstrate the essential role played by Enh13/eSR-A in both mouse and human sex determination as Enh13 deletion leads to sex reversal in the mouse and eSR-A duplications are associated with 46,XX DSD in human. It is worth bearing in mind that although eSRA was activated in all cell lines analyzed by Croft et al., [2018a], the strongest luciferase signal (over 100-fold increase) was obtained in the COS7 cells, and these were used for all the co-transfection experiments aimed to identify the factors critical for this activation. COS7 cells are fibroblast-like cells derived from monkey kidneys, which may not be the most representative cell line to study in vitro sex determination mechanisms, as shown by previous studies which used specific testis-derived cell lines some of which were also used in this study (TM3 and TM4) [Beverdam et al., 2003].

Despite these caveats, functional studies by Croft et al. [2018a] suggest that regulation of these SOX9 enhancers may be different in human and mice as SRY may be responsible for Enh13-dependent Sox9 upregulation whereas in human the ortholog eSR-A seemed to be regulated by SF1 and SOX9 but not SRY, which led the authors to propose that this enhancer was likely not involved in the initial SOX9 upregulation but rather its maintenance in the human testis. However, care should be taken when interpreting data based on cell lines where factors may already be present that could mimic the action of SRY. Together these complementary studies performed in the mouse, in cell lines, and using human pa- 
tient's data identified the critical enhancer for SOX9 regulation which is contained in the XYSR region, a hot spot of CNVs in DSD [Croft et al., 2018b; Ogawa et al., 2018].

Another region associated with CNVs and DSD was RevSex, located just downstream of XYSR and spanning a 24-kb region. Duplications in RevSex were also implicated in 46,XX DSD [Ohnesorg et al., 2017]. In search of a critical enhancer that may be contained within this region, Croft et al., [2018a] performed a luciferase assay to screen for enhancer activity 16 overlapping 2-kb fragments spanning RevSex. This led to the identification of another putative enhancer named eSR-B which was activated by SF1 and SOX9 and downregulated when FOXL2 was co-transfected with SOX9. LacZ reporter mice for eSR-B showed expression in somatic cell populations of both mouse testis and ovaries at different stages of development, however, CRISPR/Cas9 deletion did not cause sex reversal, nor were significant changes detected in the expression of key sex determination genes (Sox9, Foxl2, Wnt4) in transgenic gonads. Sequence comparison between mouse and human revealed a 75\% similarity, however, ATAC-Seq and ChIP-Seq dataset for H3K27ac did not identify any potential enhancer elements located in the mouse eSR-B equivalent, at least at embryonic stages [Maatouk et al., 2017; Garcia-Moreno et al., 2019].

These data suggest that eSR-B may be either a humanspecific enhancer, or alternatively, in mouse it may be working redundantly with other enhancers in driving SOX9 expression at later stages of gonadal development. Both eSR-A and eSR-B are activated in the absence of $S R Y$, as shown in patients where their duplications led to $46, \mathrm{XX}$ DSD. This is in contrast with what was observed for one of their mouse orthologs, Enh13, which was shown to be sequentially bound by SRY and SOX9 [Gonen et al., 2018]. A putative SRY-responsive enhancer of SOX9 was identified by Croft et al. [2018a] in human and named eALDI (alternate long-distance initiator of Sox9). This 1,259-bp fragment, located $1.4 \mathrm{~kb}$ upstream of TESCO, contained an SRY binding site, active enhancers marks in human fetal testis, and displayed an open chromatin configuration, as shown by DNaseI hypersensitivity and ChIP assays. It was also highly conserved, sharing a $78 \%$ sequence similarity with the mouse equivalent. In vitro enhancer activity assays showed that eALDI was activated by SRY+SF1 or SOX9+SF1 but not by SOX9 alone. However, when the mouse ortholog was deleted the levels of Sox9 mRNA were only partially affected within the mutant animals, which maintain Sox9 expression levels to about $40 \%$ of those in wildtype testes. These levels, as shown by Gonen et al. [2017] were not sufficiently low to induce sex reversal. This study and previous ones demonstrate that neither TESCO nor eALDI are critical in mice for SRY-induced Sox9 expression but suggest a role for eALDI in this process, at least in human. It is worth pointing out that to date no DSD patient has been found with a mutation within eALDI and/or TES/TESCO [Georg et al., 2010; Croft et al., 2018a]. However, the close proximity of eALDI and TESCO to the SOX9 coding sequence is such that if mutations or rearrangements were to be identified, they would likely include both enhancers and possibly the SOX9 coding sequence itself.

In summary, evidence from both human in vitro studies and mutant mice have shown that different SOX9 enhancers are likely to play a role either in the initial SOX9 gene activation by SRY or in SOX9 self-regulatory loop to maintain its own expression. Whilst the exact order of enhancer recruitment is still unclear, their synergistic effect is very plausible since it was shown that, at least in human cell lines, their combined expression (eSR-A+eSR$\mathrm{B}+\mathrm{eALDI}$ ) led to the greatest degree of SOX9 activation [Croft et al., 2018a].

\section{Role of 3D Chromatin Organization in SOX9 Gene Regulation}

SOX9 is quite unique as it is the only protein-coding gene with a very large $2-\mathrm{Mb}$ long topologically associated domain (TAD) [Bagheri-Fam et al., 2006; Gordon et al., 2009; Long et al., 2020]. TADs are insulated chromatin regions where contact between a defined set of enhancers to a specific promoter is established. Each TAD is a region of high interaction which is separated from the surrounding areas by boundaries that act as insulators to stop spurious enhancer-promoter interaction of neighboring genes [Dixon et al., 2012]. Effectively, each TAD works as a separate transcriptional unit and may contain clusters of co-regulated genes [Rao et al., 2014]. Evidences from both mouse and human studies of SOX9 activation suggest that chromatin looping may occur within the SOX9 TAD following binding of SRY/SF1 and SOX9/SF1 which would in turn allow direct interaction of the enhancers with the SOX9 promoter [Croft et al., 2018a; Gonen et al., 2018]. This model is supported by a study by Franke et al., [2016] which has investigated the effect of duplications within the mouse Sox9 TAD (intra-TAD) or beyond the TAD boundary (inter-TAD) on TAD morphology. Duplications of enhancer regions within the Sox9 TAD (intra-TAD) that cause female to male sex reversal in humans showed increased contact of the duplicated regions 
within the TAD, but no change in the overall TAD structure. This would result in higher Sox9 expression because of the increased physical interaction of Sox 9 enhancers with the promoter. In contrast, overlapping duplications that extended over the next boundary into the neighboring TAD (inter-TAD) resulted in the formation of a new chromatin domain (neo-TAD) insulated from the rest of the genome, with no phenotypic effect. However, incorporation of the next flanking gene, Kcnj2 in the neo-TAD resulted in ectopic contacts of Kcnj2 with the duplicated part of the Sox9 regulatory region, mis-expression of Kcnj2, and the development of a limb malformation phenotype [Franke et al., 2016]. The potential increased contact between enhancers and promoter in 46,XX DSD with SOX9 intra-TAD duplications may explain the sex reversal phenotype in the absence of $S R Y$, as the duplication may contain human-specific $S O X 9$ enhancers and result in an increased expression of SOX9 even if SRY is not present. This may also explain why deletion of the human SOX9 enhancer eALDI mouse ortholog did not lead to sex reversal in the mouse whilst being able to potentiate the SOX9 expression synergistically with the other 2 enhancers eSR-A and eSR-B in vitro. Deletion of a single enhancer is often not enough to dramatically affect expression of the gene it regulates. This is to be expected given that redundancy between multiple enhancers may be advantageous to guarantee precise expression of genes critical for developmental processes such as SOX9. Redundancy was observed for enhancers critical for limb development [Osterwalder et al., 2018], and it seems to be a trait which has evolved to confer robustness to gene regulatory networks critical for development of organs important for survival of a species such as the reproductive organs [Cannavo et al., 2016]. Characterization of the hierarchy of enhancers critical for the initial sex determination event as well as for the sex maintenance is the next challenge the field of sex determination is facing. Whilst in vitro enhancer activity assays as well as mutation analysis in mouse models and data from DSD patients have offered unique insights into which enhancers may play a role in SOX9 gene regulation, the order in which each of these enhancers are engaged into regulating SOX9 is still unknown. Novel approaches such as Chromosome Conformation Capture (3C) analysis are being developed and further optimized to work with a limited number of cells [Denker and de Laat, 2016; McCord et al., 2020]. These methods detect chromatin interactions in the cell nucleus within and between chromosomes, thus allowing to visualize enhancer interacting with one another and with gene promoter, genome-wide. The folding patterns of multiple TADs are in part mediated by compartmental interactions between active and inactive genes, as well as polycomb-mediated interactions and CTCF/Cohesinmediated interactions that result in the extrusion of a chromatin loop which may bring distant DNA fragments into close proximity [Fudenberg et al., 2016]. Analysis of the SOX9 TAD as well as a broader survey of the TAD organization within Sertoli cell nuclei may provide extremely precious information on how SOX 9 enhancers may come into close contact through chromatin looping. It is worth noting that loss of $3 \mathrm{D}$ genome organization by mean of depletion of either CTCF or Coesin seems to affect gene expression relatively less than expected [Nora et al., 2017; Rao et al., 2017].

In a recent study performed by Despang et al. [2019], a series of mouse models were generated with targeted mutations at the Sox9-Kcnj2 locus, which comprises 2 individual Sox9 and Kcnj2 TADs separated by a strong boundary. Their effect on 3D chromatin architecture as well as gene regulation and limb phenotype were then analyzed. The removal of all CTCF sites at the boundary as well as within each TAD resulted in a fusion of the Sox9-Kcnj2 TADs which, however, did not significantly affect gene regulation. In contrast, inversions and insertion of boundary elements within the TADs disturbed regulatory activity by inducing enhancer-promoter rewiring, gene expression dis-regulation, and developmental phenotypes. This study suggests that the loss of TAD insulation may have little effect on gene regulation and that enhancer-promoter communication can function independently of TADs and CTCF-mediated genome architecture. In contrast, reorganization of the $3 \mathrm{D}$ contacts by inverting the Sox9 TAD and inserting a boundary in the middle of a TAD caused a strong reduction of the contacts of Sox9 promoter with its enhancers and resulted in Sox9 misexpression. Recent studies have also proposed a model whereby transcription factors are able to activate genes by forming phase-separated condensates with coactivators that interact with their activator domains [Boija et al., 2018]. In this setup, enhancers can be brought into close proximity of a promoter by creation of transcription factor condensates, thus promoting gene activation regardless of TAD structure which may represent a facultative feature to facilitate proximity.

More research is needed to characterize TAD morphology in Sertoli cells, particularly in the context of Sox9. Analysis of TAD dynamics during embryonic testis development may provide precious information to identify the sequence of specific enhancers interacting with Sox9 promoter during the window of sex determination. 


\section{Role of Silencers}

Silencers are regulatory DNA elements that reduce transcription from their target promoters and can be considered the repressive counterparts of enhancers [Segert et al., 2021]. Similar to enhancers, silencers can be found upstream of the gene they repress, downstream of a promoter within an intronic region or exon, as well as in the $3^{\prime}$ untranslated region ( $3^{\prime}$-UTR) [Ogbourne and Antalis, 1998; Maston et al., 2006]. Enhancers and silencers may be recognized by the same transcription factor which makes it more challenging to discriminate between them [Alexandre and Vincent, 2003; White et al., 2016]. Additionally, based on the cell type and developmental stage, silencers can exhibit enhancer activity, making the traditional distinction of cis-regulatory elements as enhancers or silencers probably an over-simplification. Whilst it is now clearer which enhancers contribute to activate Sox9 expression, the role of Sox9 silencers in establishing a platform for repressors has not received much attention in the field. Sex determination is dependent on gene repression as well as gene activation [Jameson et al., 2012]; therefore, it would be informative to identify which silencers may work together to build a hub for recruiting repressors of gene expression, or perhaps, identify those Sox 9 enhancers that may play a silencer role in the female context.

The antagonistic role of FOXL2 and SOX9 in maintaining cell fate in adult gonads is well-established, but the silencers through which these transcription factors may mediate this process in either sex are still unknown. As shown in the mouse, Foxl 2 is expressed in the ovary throughout its development and adulthood and when deleted, Sox9 expression ensues [Uhlenhaut et al., 2009]. FOXL2 protein is thought to act directly on SOX9 gene expression, however, it is still not entirely understood which silencers, upstream or downstream of SOX9, FOXL2 may be binding. Given the extensive SOX9 gene desert, it is likely that, similarly to gene activation, repression of SOX9 is mediated through the use of long-range silencers. Conversely, SOX9 is thought to repress Foxl2 expression in the testis, and ChIP-Seq data in the mouse have revealed 2 SOX9-binding peaks in the Foxl2 promoter region thus likely operating in a short-range manner in this model [Rahmoun et al., 2017]. Mouse reporter lines have been invaluable to identify tissue specific enhancers within the Sox9 regulatory region. Silencer reporter assays where a putative silencer is placed upstream of an enhancer-minimal promoter driving the expression of luciferase have been used in high-throughput screen- ing in both Drosophila and human cell lines to study the effects of silencers [Huang et al., 2019; Gisselbrecht et al., 2020]. However, variable effects were often observed, and it is likely that these approaches may only be feasible to test for strong silencers.

Combinatorial approaches (ATAC-Seq, ChIP-Seq, and RNA-Seq) rather than single ones have proven to be much more effective in expanding the list of known silencers. According to the latest studies silencers were successfully identified by selecting regions of the genome that were enriched for $\mathrm{H} 3 \mathrm{~K} 27 \mathrm{me} 3$ repressive histone mark and highly interactive [Cai et al., 2021], enriched for mono-methylation of histone 4 lysine 20 (H4K20me1) [Pang and Snyder, 2020], and were in open chromatin regions adjacent to genes with low level of expression based on a RNA-Seq data [Segert et al., 2021].

Early studies have shown that FOXL2 binds to TESCO in vivo suggesting that this may be the region critical for FOXL2 recruitment and Sox9 gene repression in the ovary [Uhlenhaut et al., 2009]. However, deletion of either TES or TESCO in XX mice does not lead to female-tomale sex reversal [Gonen et al., 2017], suggesting either that earlier results may not be entirely valid or that perhaps multiple and novel Foxl2-specific enhancers/silencers may need to be recognized by FOXL2 to exert its full repressive role in the ovary and to maintain female cell fate. Additionally, ChIP-Seq analysis of FOXL2-binding pattern in embryonic mouse ovaries and adult primary granulosa cells did not find any peak within the TES region, which further corroborates the idea that FOXL2 does not bind to this region in either embryonic or adult stages [Georges et al., 2014; Nicol et al., 2018]. The Sox9specific Enh8 identified by Gonen et al.[2018] is, however, bound by FOXL2 in both embryonic ovaries at E14.5 as well as in primary granulosa cells cultured from adult ovaries [Georges et al., 2014; Nicol et al., 2018]. ATACSeq data showed that this enhancer was in an open chromatin region in both Sertoli and granulosa cells, suggesting it may contribute to the basal level of Sox9 expression seen at E11.5 in both XX and XY genital ridges, but that is also likely to be recognized by FOXL 2 and thus contribute to Sox9 repression in the ovary, as suggested by the FOXL2 ChIP-Seq experiments. Gene repression is extremely important at the bipotential genital ridge stage when both XX and XY primordial gonads present very similar transcriptomes. Indeed, according to the most recent model of what drives the bipotential gonad towards a female or male fate, a choice towards a specific fate results from tipping the balance between antagonistic/repressive signaling pathways [Kim et al., 2006; Munger et 


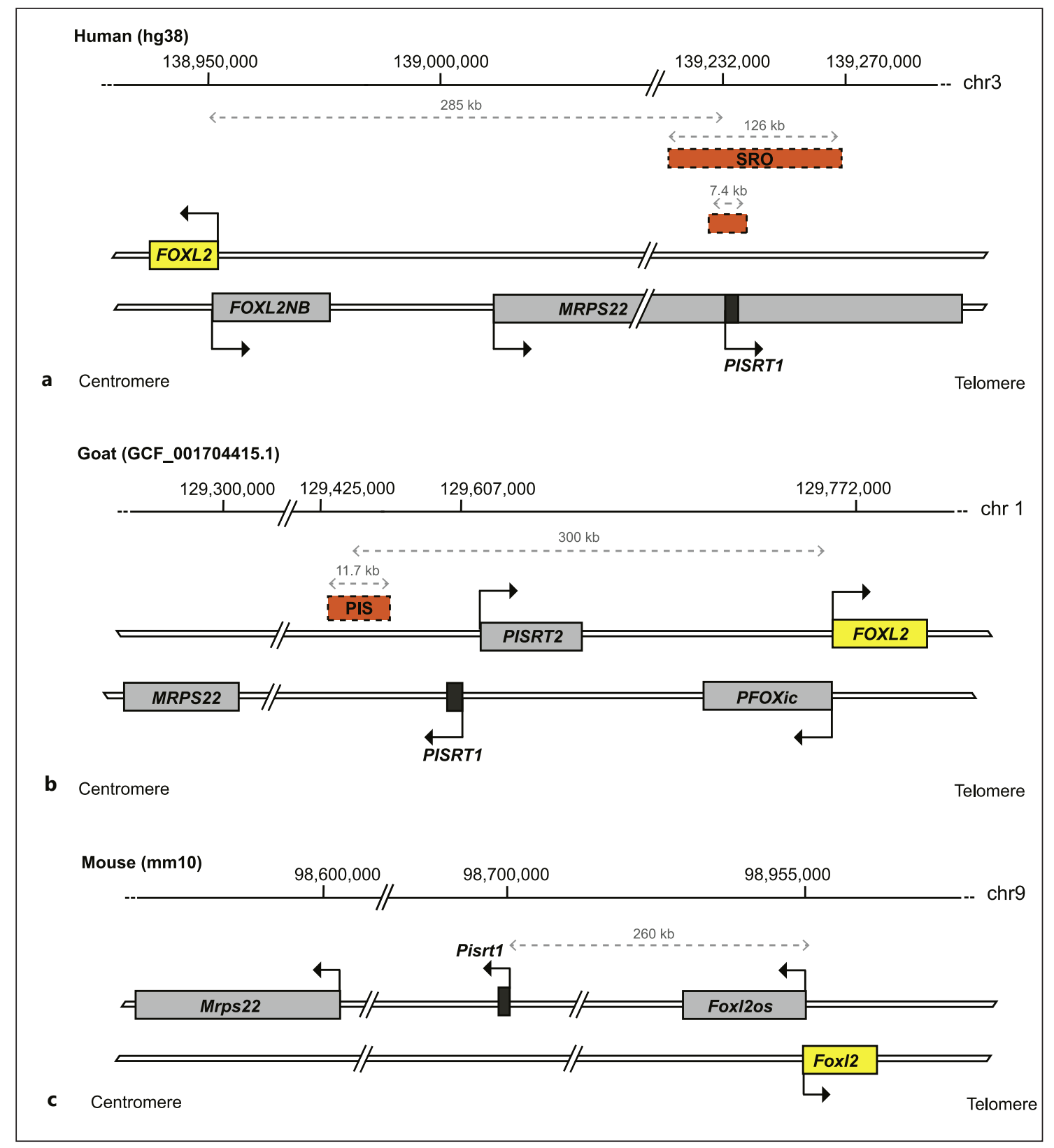

Fig. 3. Representation of the FOXL2 locus in human, goat, and mouse. Grey rectangles represent genes, orange-dotted rectangles represent genomic regions associated with chromosomal rearrangements affecting FOXL2 expression in human BPES patients and in goats with polled intersex syndrome (PIS). Image depicting the human FOXL2 locus (a) was drawn based on data from Beysen

al., 2009]. In this scenario understanding which DNA elements may recruit factors with a repressive role may offer a crucial contribution to expand our knowledge of what may repress SOX9 in the female gonad. et al. [2005] and D'Haene et al. [2009]. b In goat the deletion of the PIS region affects the expression of FOXL2 as well as nearby genes PISRT2, PISRT1, and PFOXic [Pailhoux et al., 2001]. The mouse equivalent of PFOXic is Foxl2os as reported in Cocquet et al. [2005].

\section{Long-Range Gene Regulation of FOXL2}

Whilst a lot of work has been done to characterize the gene regulation of SOX9 in the testis, less is still known about how FOXL2 may be regulated in the context of sex 
determination and maintenance in the ovary. Most of the knowledge concerning the transcriptional regulation of FOXL2 derives from studies aimed to identify the genomic rearrangements causing BPES (OMIM \#110100) in human [Crisponi et al., 2001; Beysen et al., 2005; Beysen et al., 2009; D'Haene et al., 2009]. BPES is an autosomal dominant disease, found in 1:50,000 births, characterized by a range of craniofacial defects including narrowing of the horizontal aperture of the eyelids (blepharophimosis), droopy upper lids (ptosis), medial lower eyelid ascending to the upper lid (epicanthus inversus), and an increased distance between the medial canthi (telecanthus) [Verdin and De Baere, 1993]. There are 2 types of syndromes: BPES type 1 is associated with premature ovarian insufficiency (POI) and secondary amenorrhea before the age of 40 leading to infertility in female individuals, whereas BPES type 2 does not present other phenotypic traits other than the craniofacial defects, observed in both male and female individuals. The only reported genetic defect associated with BPES is FOXL2 haploinsufficiency [Crisponi et al., 2001]. Overall, mutations within the intragenic region of FOXL2 are found in the majority of BPES patients ( $81 \%)$, and these include missense mutations, in-frame deletions, duplications, frameshift, and nonsense mutations [De Baere et al., 2001; Beysen et al., 2009]. Genomic rearrangements including deletions encompassing FOXL2 coding region and outside its coding region represent 12 and $5 \%$ of all genetic defects associated with BPES [Beysen et al., 2009; Verdin and De Baere, 2012]. Prior to the positional cloning of the FOXL2 gene [Crisponi et al., 2001], 3 balanced translocations were identified in BPES patients and located 180, 160, and 171 $\mathrm{kb}$ upstream of FOXL2, respectively [Fukushima et al., 1991; Boccone et al., 1994; Praphanphoj et al., 2000]. These genomic rearrangements disrupted 2 other genes, BPESC1 and MRPS22 [De Baere et al., 2000; Crisponi et al., 2004], although neither of these was found mutated in BPES patients, suggesting that the translocations may rather have a positional effect on FOXL2 expression, possibly by separating a long-range cis-regulatory element from the FOXL2 promoter or affecting higher-order chromatin structure [Crisponi et al., 2004].

Beysen et al. [2005] reported the first evidence of deletions outside of FOXL2 coding region in BPES patients, with a phenotype identical to individuals with intragenic mutations and found in both familial and de novo BPES cases. This study identified 5 novel deletions, 4 located $230 \mathrm{~kb}$ upstream of FOXL2 and presenting a shortest region of overlap (SRO, Fig. 3a) of $126 \mathrm{~kb}$, and one located $188 \mathrm{~kb}$ downstream of FOXL2 [Beysen et al., 2005]. The
SRO region contained several non-coding conserved sequences, possibly acting as cis-regulatory elements and it was located upstream of the translocation breakpoints identified previously [Fukushima et al., 1991; Boccone et al., 1994; Praphanphoj et al., 2000].

A later study on an additional set of individuals further narrowed down the region to a 7.4-kb fragment which, when deleted, disrupted a long ncRNA (PISRT1) and 8 conserved non-coding sequences, leading to BPES [D'Haene et al., 2009]. 3C demonstrated the functional mechanisms behind this phenotype, as the deletion was shown to disrupt the interaction between FOXL2 core promoter, the $7.4-\mathrm{kb}$ region itself, and 2 other conserved regions that may require to be in close proximity to function as a transcriptional unit [D'Haene et al., 2009]. Interestingly, the longer SRO region also contained the human ortholog of the 11.7-kb PIS locus found in the goat and located $280 \mathrm{~kb}$ upstream of the FOXL2 gene (Fig. 3b) [Pailhoux et al., 2001; Beysen et al., 2005]. Deletion of the PIS element causes polledness (absence of horns, OMIA 000483-9925) in both sexes in a dominant manner, whilst sex reversal affects only the XX goats in a recessive manner [Asdell, 1944; Pailhoux et al., 2001; Boulanger et al., 2014]. PIS mutant goats have been the subject of investigation since 1894, when the first cases of intersexuality were observed in this model [Petit, 1894]. Incidentally, many translocation breakpoints detected in humans BPES patients have been located within the chromosome region 3q23 which shows conserved synteny with the locus on chromosome 1q43 in goats that contains the PIS region [Fukushima et al., 1991; Boccone et al., 1994; Praphanphoj et al., 2000; Pailhoux et al., 2001; Alao et al., 2012; Gonzalez-Gonzalez et al., 2012; Schlade-Bartusiak et al., 2012; Yang et al., 2014], rightfully making the goat the only natural animal model for BPES [Crisponi et al., 2001].

The PIS mutation has effects on the expression of FOXL2 and 3 long non-coding RNAs (lncRNAs), namely PISRT1 (PIS regulated transcript number 1), PISRT2, and PFOXic (promoter FOXL2 inverse complementary). Among the genes affected by the PIS mutation, FOXL2 is the only one encoding for a protein. PISRT1 encodes for a $1.5-\mathrm{kb}$ transcript with a single exon, lacking an open reading frame [Pailhoux et al., 2001]. PISRT2 consists of a region of uncharacterised transcripts corresponding to sequences spanning a $\sim 100-\mathrm{kb}$ region upstream of PISRT1 [Parma et al., 2016]. PFOXic is a putative, but non-translated protein-coding gene [Pannetier et al., 2005]. In the ovary, the expression of these genes is lost in homozygous $\mathrm{PIS}^{-/-} \mathrm{XX}$ embryos, indicating a positive 
regulation by the PIS element [Franke et al., 2016]. In contrast, neither FOXL2, PISRT1, nor PFOXic are normally expressed in horn buds in wildtype animals of both sexes, but their expression is switched on in heterozygous $\mathrm{PIS}^{+-}$and homozygous $\mathrm{PIS}^{-/}$, suggesting a negative effect of the PIS region on these genes in this specific tissue context. In the eyelids, another region where FOXL2 is active, the PIS mutation did not alter its expression nor the expression of the other PIS-regulated genes, further confirming a strong tissue-dependency of the regulatory role played by the PIS locus [Pailhoux et al., 2001]. Overexpression experiments of PISRT1 were carried out in XX $\mathrm{PIS}^{-/-}$mutant goats to explore whether FOXL2 was the only responsible gene for XX sex reversal and to analyze the potential involvement of the lncRNAs in FOXL2 gene regulation [Boulanger et al., 2008]. Ectopic expression of PISRT1 in PIS ${ }^{-/-}$XX gonads did not rescue the sex reversal phenotype and did not recover FOXL2 expression. This indicated that FOXL2 loss alone may be responsible for the PIS gonadal phenotype. This was later confirmed by FOXL2 loss of function studies in goats [Boulanger et al., 2014] which showed that FOXL2 deletion by itself is sufficient to cause the sex reversal phenotype. Furthermore, expression levels of PISRT1, PISRT2, and PFOXic do not change in XX FOXL2 $2^{-/}$gonads, which makes it unlikely for altered levels of lncRNAs to play a role in the sex reversal phenotype [Boulanger et al., 2014]. These results also suggest that PISRT1 is unlikely to be involved in the regulation of FOXL2, at least when it is ectopically introduced as a transgene. This however does not exclude the possibility that PISRT1 may be involved in the cisregulation of FOXL2. This hypothesis is supported by the finding of a BPES patient with a 7.4-kb deletion (Fig. 3a) in PISRT1 associated with FOXL2 haploinsufficiency (OMIM 110100) [D'Haene et al., 2009]. PISRT1 may therefore be possibly involved in the cis-regulation of the FOXL2 gene, at least in humans.

Another gene affected by the PIS mutation is PFOXic, which is transcribed from a bidirectional promoter sustaining the transcription of both the FOXL2 and PFOXic genes [Pannetier et al., 2005]. In the mouse, PFOXic is annotated as Foxl2os, a Foxl2 anti-sense transcript possibly involved in Foxl2 gene regulation (Fig. 3c) [Cocquet et al., 2005]. However, whether or not PFOXic or PISRT1 are actually involved in the cis-regulation of FOXL2 itself is still an open question that needs to be investigated further, potentially by targeted deletion of these regions.

Studies in the mouse have also provided some clues as to the location of regulatory regions upstream of Foxl2 [Shi et al., 2014]. By performing a large-scale piggyBac
(PB) insertion mutagenesis experiment aimed to identify novel disease-related regions of the mouse genome, Shi et al. [2014] identified a region located $160 \mathrm{~kb}$ upstream of Foxl2 transcriptional start site (TSS) that, when disrupted by the insertion of the PB construct, led to growth retardation, midface hypoplasia, eyelid abnormalities, and female subfertility linked with impaired FOXL2 expression within the ovaries, thus recapitulating the human condition of BPES. A region spanning $25 \mathrm{~kb}$ flanking the $\mathrm{PB}$ insertion site contained 4 evolutionary conserved fragments (ECFs), one of which (ECF1) was localized in an open chromatin region and showed strong enhancer activity in luciferase assay. Additionally, 3C experiments conducted in maxillary and periocular cells, other 2 sites of Foxl2 expression, demonstrated a physical interaction between Foxl2 promoter and ECF1. The Fox $12^{P B / P B}$ mouse is the only model described to date that might help understand more about the regions regulating Foxl2 expression in the mouse.

\section{Future Developments and Open Questions}

The regulation of key gonadal genes such as SOX9 and FOXL2 deserves a more systematic investigation. Most of the studies investigating the chromatin landscape of male and female gonads carried out so far and aimed to define the critical enhancers of Sox 9 were performed at embryonic stages [Gonen et al., 2018; Garcia-Moreno et al., 2019]. We know, however, that SOX9 expression has to be maintained throughout life in the testis so that FOXL2 and the downstream female pathways are continuously repressed. The enhancers involved in adult gonadal sex maintenance are still unknown. Future studies aimed to characterize the chromatin landscape throughout ovarian and testis development and adulthood paired with ChIP-Seq analysis of active and repressive histone marks, as well as of critical transcription factors such as SOX9, FOXL2, and DMRT1 may reveal the regulatory elements critical for establishment and maintenance of gonadal cell sex fate (see Figure 4 for a proposed approach). Much more is still to be discovered especially for what concerns FOXL2 regulation. While seminal studies demonstrated that the PIS region is regulating FOXL2 expression in the goat, there are still no data indicating whether a conserved mechanism may exist in the mouse. No study has followed up so far and used the Fox $12^{P B / P B}$ model to understand more about Foxl 2 enhancers in the mouse. New models of targeted deletions of ovarian-specific enhancers are yet to be developed. However, omics studies on 


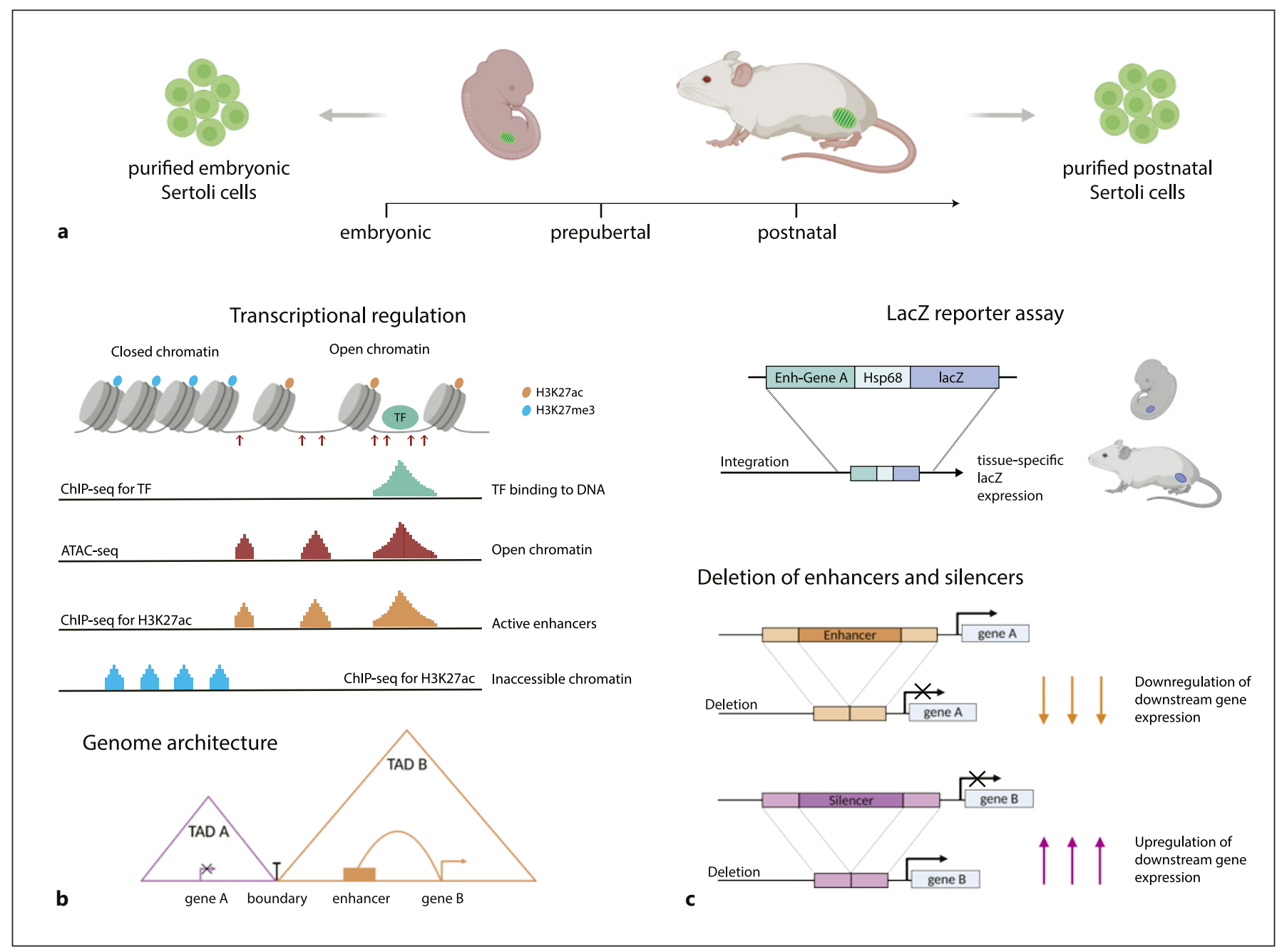

Fig. 4. Combinatorial approach to explore gonad-specific regulation of Sox9. a Purification of Sertoli cells using fluorescent reporters throughout embryonic and postnatal life. $\mathbf{b}$ Identification of regulatory elements of Sox 9 by exploring chromatin landscape, combining ATAC-seq, ChIP-seq for histone marks, and ChIP-seq for transcription factors. Identification of 3D genome architecture of Sertoli cells by defining topologically associated domains (TADs). c Characterization of novel enhancers by utilizing lacZ reporter assays and deleting specific enhancers (single or combination) or specific silencers. Created with BioRender.com. embryonic gonads already exist [Garcia-Moreno et al., 2019], and these could be further explored to define critical regulatory elements and to create more precise models. Outstanding questions still remain that could be answered by refining the goat PIS model. It would be interesting to narrow down further the PIS region to identify the genomic fragment crucial for FOXL2 expression which may not affect the other PIS-dependent genes and to understand if and how PISRT1 and PFOXic may be involved in FOXL2 gene regulation by targeted deletion. In the mouse, which is also used as a model for human BPES, although this phenotype is seen only in Foxl2 homozy-

Enhancers and Sex Determination gotes, the relevant regulatory regions for both the gonads and eyelids remain a mystery. A combinatorial multiomics approach could be utilized to decipher which regions are responsible for the regulation of the Foxl2 gene in the mouse. The comparison with the goat data may reveal whether they correlate with the PIS region, or if they represent novel short or long-range regulatory elements. Because silencers may act as enhancers in different cell types and developmental stages, it is critical that any ChIP-Seq profiling of histone marks or other epigenome survey approaches are carried out on purified cell types collected at precise time points across gonadal develop- 
ment of both ovaries and testes. A major obstacle to this comparison is the current lack of mouse reporter lines for the selection of somatic cell populations of the ovary throughout development.

Systematic approaches could reveal enhancers/silencers involved not only in DSD but also in thus far unexplained cases of infertility where sub-threshold defects in the somatic cell environment may have a detrimental impact on germ cell development. Assays for chromatin dynamics coupled with proteomic approaches to systematically identify changes in chromatin-bound proteins over time should also provide more comprehensive understanding of both sex determination and gonadal maintenance.

All studies that have looked at the epigenome of mouse gonads have been conducted in bulk tissue samples. It is now feasible and it will be worthwhile in the future to expand single-cell epigenomics approaches to the sex determination field [Shema et al., 2019]. These approaches may reveal if the opening and closing of specific enhancers, and perhaps also the binding of specific factors, occurs simultaneously in all cells or if it arises in a group of cells and then it is propagated to the others.

Because SRY, acting together with SF1, is the only known activator of SOX 9 at the time of sex determination in mammals, another critical experiment still outstanding in the field is to carry out SRY ChIP-Seq that would provide invaluable information on which enhancers are used by SRY at the earliest stages of male sex determination. This could potentially reveal more regulatory regions important for SOX9 expression, besides Enh13. Additionally, a timecourse analysis of SOX9 genomic binding sites in the testes may also reveal which enhancers are likely to be used by SOX9 itself for the maintenance of its own expression throughout testis development up to adulthood. Deletion of Enh13 leads to development of fully sex-reversed XY females with ovaries expressing FOXL2. It would be interesting to find out which genomic regions, especially upstream of SOX9, FOXL2 binds to in this genetic context, and if those regions are the same as in a wildtype XX ovary. These experiments may help to further define the regulatory region of SOX 9 and identify silencers involved in its repression in the female context.

As mentioned, the $\mathrm{SOX} 9$ regulatory region is of considerable size but fully contained within a single TAD. Currently, no study exists which focuses on the 3D genome architecture of Sertoli and granulosa cells and how it may change during the process of sex determination. Whilst ATAC-Seq and ChIP-Seq analysis of gonadal cells during the window of sex determination has provided a wealth of information on putative enhancers, an in-depth study of the TAD organization in these cells may help to identify which regulatory elements are more likely to work synergistically because they are part of the same TAD. It would also be insightful to perform 3D analysis of the genome following deletion or duplication of specific enhancers to model the genomic rearrangements found in DSD cases. Could these changes impair the morphology of a specific TAD, specifically that of SOX9, and could this be a mechanism leading to DSD? More work should be done to analyze how the SOX9 TAD reorganizes itself in the absence of critical enhancers such as Enh13, as well as after the deletion of multiple enhancers which may have a more cooperative role in maintaining and establishing SOX9 expression in the testis. Highly interacting areas of a TAD may be scanned for enrichment for particular transcription factors binding sites at different stages of gonadal development as an additional approach to gain an idea of when a specific factor may be binding to SOX9 regulatory region. Mouse models have offered invaluable opportunities to explore the SOX9 regulatory landscape and it appears that some elements may be conserved between mouse and human. Nevertheless, others may be species-specific and redundancy between enhancers is also likely, especially in humans, since this would confer robustness to the system, which might be expected for a gene so critical for healthy reproduction. However, this makes the study of enhancers important in sex determination that much trickier and perhaps impossible, until we manage to systematically survey the epigenetic landscape of human gonads during the window of sex determination. Optimization of an in vitro human gonadal development model could help the identification of enhancers critical for at least the very early stages of sex determination, which are currently almost impossible to research.

\section{Acknowledgements}

This work was supported by the Francis Crick Institute which receives its core funding from Cancer Research UK (FC001107), the UK Medical Research Council (FC001107), and the Wellcome Trust (FC001107). We are grateful to Dr Silvana Guioli for critical reading of the manuscript and for providing helpful suggestions.

\section{Conflict of Interest Statement}

The authors have no conflicts of interest to declare. 


\section{Funding Sources}

This work was supported by the Francis Crick Institute which receives its core funding from Cancer Research UK (FC001107), the UK Medical Research Council (FC001107), and the Wellcome Trust (FC001107).

\section{Author Contributions}

R.M. conceptualised the review. R.M. and M.N. wrote the initial draft. R.M., M.N., and R.L.-B. contributed to the critical reading of the review. All authors contributed to the article and approved the submitted version.

\section{References}

Akiyama H, Chaboissier MC, Martin JF, Schedl A, de Crombrugghe B. The transcription factor Sox9 has essential roles in successive steps of the chondrocyte differentiation pathway and is required for expression of Sox 5 and Sox6. Genes Dev. 2002;16:2813-28.

Alao MJ, Lalèyè A, Lalya F, Hans C, Abramovicz M, Morice-Picard F, et al. Blepharophimosis, ptosis, epicanthus inversus syndrome with translocation and deletion at chromosome 3 q23 in a black African female. Eur J Med Genet. 2012;55:630-4.

Alexandre C, Vincent JP. Requirements for transcriptional repression and activation by Engrailed in Drosophila embryos. Development. 2003;130:729-39.

Arboleda VA, Fleming A, Barseghyan H, Délot E, Sinsheimer JS, Vilain E. Regulation of sex determination in mice by a non-coding genomic region. Genetics. 2014;197:885-97.

Asdell SA. The genetic sex of intersexual goats and a probable linkage with the gene for Hornlessness. Science. 1944;99:124.

Baetens D, Mendonça BB, Verdin H, Cools M, De Baere E. Non-coding variation in disorders of sex development. Clin Genet. 2017;91:16372.

Bagheri-Fam S, Barrionuevo F, Dohrmann U, Günther T, Schüle R, Kemler R, et al. Longrange upstream and downstream enhancers control distinct subsets of the complex spatiotemporal Sox9 expression pattern. Dev Biol. 2006;291:382-97.

Bardoni B, Zanaria E, Guioli S, Floridia G, Worley $\mathrm{KC}$, Tonini G, et al. A dosage sensitive locus at chromosome Xp21 is involved in male to female sex reversal. Nat Genet. 1994;7:497501.

Barrionuevo F, Bagheri-Fam S, Klattig J, Kist R, Taketo MM, Englert C, et al. Homozygous inactivation of Sox 9 causes complete XY sex reversal in mice. Biol Reprod. 2006;74:195-201.

Barrionuevo F, Georg I, Scherthan H, Lécureuil C, Guillou F, Wegner M, et al. Testis cord differentiation after the sex determination stage is independent of Sox 9 but fails in the combined absence of Sox9 and Sox8. Dev Biol. 2009;327: 301-12.

Barrionuevo FJ, Hurtado A, Kim GJ, Real FM, Bakkali M, Kopp JL, et al. Sox9 and Sox8 protect the adult testis from male-to-female genetic reprogramming and complete degeneration. Elife. 2016;5:e15635.
Benko S, Fantes JA, Amiel J, Kleinjan DJ, Thomas $S$, Ramsay J, et al. Highly conserved non-coding elements on either side of SOX9 associated with Pierre Robin sequence. Nat Genet. 2009;41:359-64.

Benko S, Gordon CT, Mallet D, Sreenivasan R, Thauvin-Robinet C, Brendehaug A, et al. Disruption of a long distance regulatory region upstream of SOX9 in isolated disorders of sex development. J Med Genet. 2011;48:825-30.

Bernard P, Ryan J, Sim H, Czech DP, Sinclair AH, Koopman $\mathrm{P}$, et al. Wnt signaling in ovarian development inhibits Sf1 activation of Sox9 via the Tesco enhancer. Endocrinology. 2012; 153:901-12.

Berta P, Hawkins JR, Sinclair AH, Taylor A, Griffiths BL, Goodfellow PN, et al. Genetic evidence equating SRY and the testis-determining factor. Nature. 1990;348:448-50.

Beverdam A, Wilhelm D, Koopman P. Molecular characterization of three gonad cell lines. Cytogenet Genome Res. 2003;101:242-9.

Beysen D, Raes J, Leroy BP, Lucassen A, Yates JR, Clayton-Smith J, et al. Deletions involving long-range conserved nongenic sequences upstream and downstream of FOXL2 as a novel disease-causing mechanism in blepharophimosis syndrome. Am J Hum Genet. 2005;77:205-18.

Beysen D, De Paepe A, De Baere E. FOXL2 mutations and genomic rearrangements in BPES. Hum Mutat. 2009;30:158-69.

Bi W, Deng JM, Zhang Z, Behringer RR, de Crombrugghe B. Sox9 is required for cartilage formation. Nat Genet. 1999;22:85-9.

Bishop CE, Whitworth DJ, Qin Y, Agoulnik AI, Agoulnik IU, Harrison WR, et al. A transgenic insertion upstream of Sox 9 is associated with dominant XX sex reversal in the mouse. Nat Genet. 2000;26:490-4.

Boccone L, Meloni A, Falchi AM, Usai V, Cao A. Blepharophimosis, ptosis, epicanthus inversus syndrome, a new case associated with de novo balanced autosomal translocation $[46, X Y, t(3 ; 7)(\mathrm{q} 23 ; \mathrm{q} 32)]$. Am J Med Genet. 1994;51:258-9.

Boija A, Klein IA, Sabari BR, Dall'Agnese A, Coffey EL, Zamudio AV, et al. Transcription factors activate genes through the phase-separation capacity of their activation domains. Cell. 2018;175:1842-e16.

Boulanger L, Kocer A, Daniel N, Pannetier M, Chesné P, Heyman Y, et al. Attempt to rescue sex-reversal by transgenic expression of the PISRT1 gene in XX PIS-/- goats. Sex Dev. 2008;2:142-51.
Boulanger L, Pannetier M, Gall L, Allais-Bonnet A, Elzaiat M, Le Bourhis D, et al. FOXL2 is a female sex-determining gene in the goat. Curr Biol. 2014;24:404-8.

Bowles J, Schepers G, Koopman P. Phylogeny of the SOX family of developmental transcription factors based on sequence and structural indicators. Dev Biol. 2000;227:239-55.

Buganim Y, Itskovich E, Hu YC, Cheng AW, Ganz K, Sarkar S, et al. Direct reprogramming of fibroblasts into embryonic Sertoli-like cells by defined factors. Cell Stem Cell. 2012;11: 373-86.

Bullejos M, Koopman P. Spatially dynamic expression of Sry in mouse genital ridges. Dev Dyn. 2001;221:201-5.

Bullejos M, Koopman P. Delayed Sry and Sox9 expression in developing mouse gonads underlies B6-Y(DOM) sex reversal. Dev Biol. 2005;278:473-81.

Cai Y, Zhang Y, Loh YP, Tng JQ, Lim MC, Cao Z, et al. H3K27me3-rich genomic regions can function as silencers to repress gene expression via chromatin interactions. Nat Commun. 2021;12(1):719.

Cannavo E, Khoueiry P, Garfield DA, Geeleher P, Zichner T, Gustafson EH, et al. Shadow enhancers are pervasive features of developmental regulatory networks. Curr Biol. 2016; 26:38-51.

Chaboissier MC, Kobayashi A, Vidal VI, Lützkendorf S, van de Kant HJ, Wegner M, et al. Functional analysis of Sox8 and Sox9 during sex determination in the mouse. Development. 2004;131:1891-901.

Cocquet J, Pannetier M, Fellous M, Veitia RA. Sense and antisense Foxl2 transcripts in mouse. Genomics. 2005;85:531-41.

Correa SM, Washburn LL, Kahlon RS, Musson MC, Bouma GJ, Eicher EM, et al. Sex reversal in C57BL/6J XY mice caused by increased expression of ovarian genes and insufficient activation of the testis determining pathway. PLoS Genet. 2012;8:e1002569.

Cox JJ, Willatt L, Homfray T, Woods CG. A SOX9 duplication and familial 46,XX developmental testicular disorder. N Engl J Med. 2011; 364:91-3.

Crisponi L, Deiana M, Loi A, Chiappe F, Uda M, Amati $\mathrm{P}$, et al. The putative forkhead transcription factor FOXL2 is mutated in blepharophimosis/ptosis/epicanthus inversus syndrome. Nat Genet. 2001;27:159-66. 
Crisponi L, Uda M, Deiana M, Loi A, Nagaraja R, Chiappe $\mathrm{F}$, et al. FOXL2 inactivation by a translocation $171 \mathrm{~kb}$ away: analysis of $500 \mathrm{~kb}$ of chromosome 3 for candidate long-range regulatory sequences. Genomics. 2004;83: 757-64.

Croft B, Ohnesorg T, Hewitt J, Bowles J, Quinn A, Tan J, et al. Human sex reversal is caused by duplication or deletion of core enhancers upstream of SOX9. Nat Commun. 2018a;9:5319.

Croft B, Ohnesorg T, Sinclair AH. The role of copy number variants in disorders of sex development. Sex Dev. 2018b;12:19-29.

De Baere E, Fukushima Y, Small K, Udar N, Van Camp G, Verhoeven K, et al. Identification of BPESC1, a novel gene disrupted by a balanced chromosomal translocation, $\mathrm{t}(3 ; 4)$ (q23; p15.2), in a patient with BPES. Genomics. 2000;68:296-304.

De Baere E, Dixon MJ, Small KW, Jabs EW, Leroy BP, Devriendt K, et al. Spectrum of FOXL2 gene mutations in blepharophimosis-ptosisepicanthus inversus (BPES) families demonstrates a genotype--phenotype correlation. Hum Mol Genet. 2001;10:1591-600.

Delot EC, Vilain E. Towards improved genetic diagnosis of human differences of sex development. Nat Rev Genet. 2021;22:588-602.

Denker A, de Laat W. The second decade of 3C technologies: detailed insights into nuclear organization. Genes Dev. 2016;30:1357-82.

Despang A, Schöpflin R, Franke M, Ali S, Jerković I, Paliou C, et al. Functional dissection of the Sox9-Kcnj2 locus identifies nonessential and instructive roles of TAD architecture. Nat Genet. 2019;51:1263-71.

D'Haene B, Attanasio C, Beysen D, Dostie J, Lemire E, Bouchard P, et al. Disease-causing $7.4 \mathrm{~kb}$ cis-regulatory deletion disrupting conserved non-coding sequences and their interaction with the FOXL2 promotor: implications for mutation screening. PLoS Genet. 2009; 5:e1000522.

Dixon JR, Selvaraj S, Yue F, Kim A, Li Y, Shen Y, et al. Topological domains in mammalian genomes identified by analysis of chromatin interactions. Nature. 2012;485:376-80.

Eggers S, Sadedin S, van den Bergen JA, Robevska G, Ohnesorg T, Hewitt J, et al. Disorders of sex development: insights from targeted gene sequencing of a large international patient cohort. Genome Biol. 2016;17:243.

Eggers S, Sinclair A. Mammalian sex determination - insights from humans and mice. Chromosome Res. 2012;20:215-38.

Eicher EM, Washburn LL, Schork NJ, Lee BK, Shown EP, Xu X, et al. Sex-determining genes on mouse autosomes identified by linkage analysis of C57BL/6J-YPOS sex reversal. Nat Genet. 1996;14:206-9.

Foster JW, Dominguez-Steglich MA, Guioli S, Kwok C, Weller PA, Stevanović M, et al. Campomelic dysplasia and autosomal sex reversal caused by mutations in an SRY-related gene. Nature. 1994;372:525-30.
Franke M, Ibrahim DM, Andrey G, Schwarzer W, Heinrich V, Schöpflin R, et al. Formation of new chromatin domains determines pathogenicity of genomic duplications. Nature. 2016; 538:265-9.

Fudenberg G, Imakaev M, Lu C, Goloborodko A, Abdennur N, Mirny LA. Formation of chromosomal domains by loop extrusion. Cell Rep. 2016;15:2038-49.

Fukushima Y, Wakui K, Nishida T, Ueoka Y. Blepharophimosis sequence and de novo balanced autosomal translocation $[46, \mathrm{XY}, \mathrm{t}(3 ; 4)$ (q23;p15.2)]: possible assignment of the trait to 3q23. Am J Med Genet. 1991;40:485-7.

Garcia-Moreno SA, Futtner CR, Salamone IM, Gonen N, Lovell-Badge R, Maatouk DM. Gonadal supporting cells acquire sex-specific chromatin landscapes during mammalian sex determination. Dev Biol. 2019;446:168-79.

Georg I, Bagheri-Fam S, Knower KC, Wieacker P, Scherer G, Harley VR. Mutations of the SRYresponsive enhancer of SOX9 are uncommon in XY gonadal dysgenesis. Sex Dev. 2010;4: $321-5$.

Georges A, L'Hôte D, Todeschini AL, Auguste A, Legois B, Zider A, et al. The transcription factor FOXL2 mobilizes estrogen signaling to maintain the identity of ovarian granulosa cells. Elife. 2014;3:e04207.

Gisselbrecht SS, Palagi A, Kurland JV, Rogers JM, Ozadam H, Zhan Y, et al. Transcriptional silencers in Drosophila serve a dual role as transcriptional enhancers in alternate cellular contexts. Mol Cell. 2020;77:324-e8.

Gonen N, Quinn A, O'Neill HC, Koopman P, Lovell-Badge R. Correction: Normal levels of Sox9 expression in the developing mouse testis depend on the TES/TESCO enhancer, but this does not act alone. PLoS Genet. 2017;13: e1006584.

Gonen N, Futtner CR, Wood S, Garcia-Moreno SA, Salamone IM, Samson SC, et al. Sex reversal following deletion of a single distal enhancer of Sox9. Science. 2018;360:1469-73.

Gonzalez-Gonzalez C, Garcia-Hoyos M, Hernaez Calzon R, Arroyo Diaz C, Gonzalez Fanego C, Lorda Sanchez I, et al. Microdeletion found by array-CGH in girl with blepharophimosis syndrome and apparently balanced translocation $\mathrm{t}(3 ; 15)(\mathrm{q} 23 ; \mathrm{q} 25)$. Ophthalmic Genet. 2012;33:107-10.

Gordon CT, Tan TY, Benko S, Fitzpatrick D, Lyonnet S, Farlie PG. Long-range regulation at the SOX9 locus in development and disease. J Med Genet. 2009;46:649-56.

Gubbay J, Collignon J, Koopman P, Capel B, Economou A, Münsterberg A, et al. A gene mapping to the sex-determining region of the mouse $\mathrm{Y}$ chromosome is a member of a novel family of embryonically expressed genes. $\mathrm{Na}$ ture. 1990;346:245-50.

Harris ML, Baxter LL, Loftus SK, Pavan WJ. Sox proteins in melanocyte development and melanoma. Pigment Cell Melanoma Res. 2010;23:496-513.
Haseeb A, Lefebvre V. The SOXE transcription factors-SOX8, SOX9 and SOX10-share a bipartite transactivation mechanism. Nucleic Acids Res. 2019;47:6917-31.

Hiramatsu R, Matoba S, Kanai-Azuma M, Tsunekawa N, Katoh-Fukui Y, Kurohmaru $\mathrm{M}$, et al. A critical time window of Sry action in gonadal sex determination in mice. Development. 2009;136:129-38.

Huang B, Wang S, Ning Y, Lamb AN, Bartley J. Autosomal XX sex reversal caused by duplication of SOX9. Am J Med Genet. 1999;87:349_ 53.

Huang D, Petrykowska HM, Miller BF, Elnitski L, Ovcharenko I. Identification of human silencers by correlating cross-tissue epigenetic profiles and gene expression. Genome Res. 2019;29:657-67.

Hyon C, Chantot-Bastaraud S, Harbuz R, Bhouri $\mathrm{R}$, Perrot N, Peycelon M, et al. Refining the regulatory region upstream of SOX9 associated with 46,XX testicular disorders of Sex Development (DSD). Am J Med Genet A. 2015;167A:1851-8.

Ioannidis J, Taylor G, Zhao D, Liu L, Idoko-Akoh A, Gong $\mathrm{D}$, et al. Primary sex determination in birds depends on DMRT1 dosage, but gonadal sex does not determine adult secondary sex characteristics. Proc Natl Acad Sci U S A. 2021;118(10).

Jakobsen LP, Ullmann R, Christensen SB, Jensen KE, Mølsted K, Henriksen KF, et al. Pierre Robin sequence may be caused by dysregulation of SOX9 and KCNJ2. J Med Genet. 2007; 44:381-6.

Jameson SA, Natarajan A, Cool J, DeFalco T, Maatouk DM, Mork L, et al. Temporal transcriptional profiling of somatic and germ cells reveals biased lineage priming of sexual fate in the fetal mouse gonad. PLoS Genet. 2012;8: e1002575.

Jeays-Ward K, Hoyle C, Brennan J, Dandonneau M, Alldus G, Capel B, et al. Endothelial and steroidogenic cell migration are regulated by WNT4 in the developing mammalian gonad. Development. 2003;130:3663-70.

Jo A, Denduluri S, Zhang B, Wang Z, Yin L, Yan $Z$, et al. The versatile functions of Sox9 in development, stem cells, and human diseases. Genes Dis. 2014;1:149-61.

Jordan BK, Mohammed M, Ching ST, Délot E, Chen XN, Dewing P, et al. Up-regulation of WNT-4 signaling and dosage-sensitive sex reversal in humans. Am J Hum Genet. 2001;68: 1102-9.

Kent J, Wheatley SC, Andrews JE, Sinclair AH, Koopman P. A male-specific role for SOX9 in vertebrate sex determination. Development. 1996;122:2813-22.

Kim GJ, Sock E, Buchberger A, Just W, Denzer F, Hoepffner W, et al. Copy number variation of two separate regulatory regions upstream of SOX9 causes isolated $46, \mathrm{XY}$ or $46, \mathrm{XX}$ disorder of sex development. J Med Genet. 2015; 52:240-7. 
Kim Y, Kobayashi A, Sekido R, DiNapoli L, Brennan J, Chaboissier MC, et al. Fgf9 and Wnt4 act as antagonistic signals to regulate mammalian sex determination. PLoS Biol. 2006;4: e187.

Koopman P, Gubbay J, Vivian N, Goodfellow P, Lovell-Badge R. Male development of chromosomally female mice transgenic for Sry. Nature. 1991;351:117-21.

Kwok C, Weller PA, Guioli S, Foster JW, Mansour S, Zuffardi O, et al. Mutations in SOX9, the gene responsible for campomelic dysplasia and autosomal sex reversal. Am J Hum Genet. 1995;57:1028-36.

Lambeth LS, Raymond CS, Roeszler KN, Kuroiwa A, Nakata T, Zarkower D, et al. Over-expression of DMRT1 induces the male pathway in embryonic chicken gonads. Dev Biol. 2014; 389:160-72.

Lee $\mathrm{CH}$, Taketo $\mathrm{T}$. Normal onset, but prolonged expression, of Sry gene in the B6.YDOM sexreversed mouse gonad. Dev Biol. 1994;165: $442-52$.

Li Y, Zheng M, Lau YF. The sex-determining factors SRY and SOX9 regulate similar target genes and promote testis cord formation during testicular differentiation. Cell Rep. 2014; 8:723-33.

Lindeman RE, Murphy MW, Agrimson KS, Gewiss RL, Bardwell VJ, Gearhart MD, et al The conserved sex regulator DMRT1 recruits SOX9 in sexual cell fate reprogramming. $\mathrm{Nu}-$ cleic Acids Res. 2021;49(11):6144-64.

Long HK, Osterwalder M, Welsh IC, Hansen K, Davies JOJ, Liu YE, et al. Loss of extreme longrange enhancers in human neural crest drives a craniofacial disorder. Cell Stem Cell. 2020; 27:765-e14.

Lovell-Badge R, Robertson E. XY female mice resulting from a heritable mutation in the primary testis-determining gene, Tdy. Development. 1990;109:635-46.

Ludbrook LM, Bernard P, Bagheri-Fam S, Ryan J, Sekido R, Wilhelm D, et al. Excess DAX1 leads to XY ovotesticular disorder of sex development (DSD) in mice by inhibiting steroidogenic factor-1 (SF1) activation of the testis enhancer of SRY-box-9 (Sox9). Endocrinology. 2012;153:1948-58.

Maatouk DM, DiNapoli L, Alvers A, Parker KL, Taketo MM, Capel B. Stabilization of betacatenin in XY gonads causes male-to-female sex-reversal. Hum Mol Genet. 2008;17:294955.

Maatouk DM, Natarajan A, Shibata Y, Song L, Crawford GE, Ohler U, et al. Genome-wide identification of regulatory elements in Sertoli cells. Development. 2017;144:720-30.

Maston GA, Evans SK, Green MR. Transcriptional regulatory elements in the human genome. Annu Rev Genomics Hum Genet. 2006;7:29_ 59.

Matson CK, Murphy MW, Sarver AL, Griswold MD, Bardwell VJ, Zarkower D. DMRT1 prevents female reprogramming in the postnatal mammalian testis. Nature. 2011;476:101-4.
McCord RP, Kaplan N, Giorgetti L. Chromosome conformation capture and beyond: Toward an integrative view of chromosome structure and function. Mol Cell. 2020;77:688-708.

Mertin S, McDowall SG, Harley VR. The DNAbinding specificity of SOX9 and other SOX proteins. Nucleic Acids Res. 1999;27:135964.

Moniot B, Declosmenil F, Barrionuevo F, Scherer G, Aritake K, Malki S, et al. The PGD2 pathway, independently of FGF9, amplifies SOX9 activity in Sertoli cells during male sexual differentiation. Development. 2009;136:181321.

Morais da Silva S, Hacker A, Harley V, Goodfellow P, Swain A, Lovell-Badge R. Sox9 expression during gonadal development implies a conserved role for the gene in testis differentiation in mammals and birds. Nat Genet. 1996; 14:62-8.

Moreno-Mendoza N, Harley VR, Merchant-Larios H. Differential expression of SOX9 in gonads of the sea turtle Lepidochelys olivacea at male- or female-promoting temperatures. J Exp Zool. 1999;284:705-10.

Munger SC, Aylor DL, Syed HA, Magwene PM, Threadgill DW, Capel B. Elucidation of the transcription network governing mammalian sex determination by exploiting strain-specific susceptibility to sex reversal. Genes Dev. 2009;23:2521-36.

Nicol B, Grimm SA, Gruzdev A, Scott GJ, Ray MK, Yao HH. Genome-wide identification of FOXL2 binding and characterization of FOXL2 feminizing action in the fetal gonads. Hum Mol Genet. 2018;27:4273-87.

Nora EP, Goloborodko A, Valton AL, Gibcus JH, Uebersohn A, Abdennur N, et al. Targeted degradation of CTCF decouples local insulation of chromosome domains from genomic compartmentalization. Cell. 2017;169:930e22.

Ogawa Y, Terao M, Hara S, Tamano M, Okayasu $\mathrm{H}$, Kato T, et al. Mapping of a responsible region for sex reversal upstream of Sox 9 by production of mice with serial deletion in a genomic locus. Sci Rep. 2018;8:17514.

Ogbourne S, Antalis TM. Transcriptional control and the role of silencers in transcriptional regulation in eukaryotes. Biochem J. 1998;331 ( Pt 1)(Pt 1):1-14.

Ohnesorg T, van den Bergen JA, Belluoccio D, Shankara-Narayana N, Kean AM, Vasilaras A, et al. A duplication in a patient with $46, \mathrm{XX}$ ovo-testicular disorder of sex development refines the SOX9 testis-specific regulatory region to $24 \mathrm{~kb}$. Clin Genet. 2017;92:347-9.

Osterwalder M, Barozzi I, Tissières V, FukudaYuzawa Y, Mannion BJ, Afzal SY, et al. Enhancer redundancy provides phenotypic robustness in mammalian development. Nature. 2018;554:239-43.

Pailhoux E, Vigier B, Chaffaux S, Servel N, Taourit S, Furet JP, et al. A 11.7-kb deletion triggers intersexuality and polledness in goats. Nat Genet. 2001;29:453-8.
Pang B, Snyder MP. Systematic identification of silencers in human cells. Nat Genet. 2020;52: 254-63.

Pannetier M, Renault L, Jolivet G, Cotinot C, Pailhoux E. Ovarian-specific expression of a new gene regulated by the goat PIS region and transcribed by a FOXL2 bidirectional promoter. Genomics. 2005;85:715-26.

Parivesh A, Barseghyan H, Délot E, Vilain E. Translating genomics to the clinical diagnosis of disorders/differences of sex development. Curr Top Dev Biol. 2019;134:317-75.

Parma P, Radi O, Vidal V, Chaboissier MC, Dellambra E, Valentini S, et al. R-spondin1 is essential in sex determination, skin differentiation and malignancy. Nat Genet. 2006;38: 1304-9.

Parma P, Veyrunes F, Pailhoux E. Sex reversal in non-human placental mammals. Sex Dev. 2016;10:326-44.

Petit G. Nouvelle observation d'hermaphrodisme complexe des voies génitales chez un bouc. Recl Med Vét Ec Alfort. 1894;71:247-9.

Praphanphoj V, Goodman BK, Thomas GH, Niel KM, Toomes C, Dixon MJ, et al. Molecular cytogenetic evaluation in a patient with a translocation $(3 ; 21)$ associated with blepharophimosis, ptosis, epicanthus inversus syndrome (BPES). Genomics. 2000;65:67-9.

Qin Y, Bishop CE. Sox9 is sufficient for functional testis development producing fertile male mice in the absence of Sry. Hum Mol Genet. 2005;14:1221-9.

Qin Y, Kong LK, Poirier C, Truong C, Overbeek PA, Bishop CE. Long-range activation of Sox 9 in Odd Sex (Ods) mice. Hum Mol Genet. 2004;13:1213-8.

Rahmoun M, Lavery R, Laurent-Chaballier S, Bellora N, Philip GK, Rossitto M, et al. In mammalian foetal testes, SOX9 regulates expression of its target genes by binding to genomic regions with conserved signatures. Nucleic Acids Res. 2017;45:7191-211.

Rao SS, Huntley MH, Durand NC, Stamenova EK, Bochkov ID, Robinson JT, et al. A 3D map of the human genome at kilobase resolution reveals principles of chromatin looping. Cell. 2014;159:1665-80.

Rao SSP, Huang SC, Glenn St Hilaire B, Engreitz JM, Perez EM, Kieffer-Kwon KR, et al. Cohesin loss eliminates all loop domains. Cell. 2017;171:305-e24.

Schepers GE, Bullejos M, Hosking BM, Koopman P. Cloning and characterisation of the Sry-related transcription factor gene Sox8. Nucleic Acids Res. 2000;28:1473-80.

Schepers GE, Teasdale RD, Koopman P. Twenty pairs of sox: extent, homology, and nomenclature of the mouse and human sox transcription factor gene families. Dev Cell. 2002; $3: 167-70$ 
Schlade-Bartusiak K, Brown L, Lomax B, Bruyère H, Gillan T, Hamilton S, et al. BPES with atypical premature ovarian insufficiency, and evidence of mitotic recombination, in a woman with trisomy $\mathrm{X}$ and a translocation $\mathrm{t}(3 ; 11)$ (q22.3;q14.1). Am J Med Genet A. 2012;158A: 2322-7.

Schouten JP, McElgunn CJ, Waaijer R, Zwijnenburg D, Diepvens F, Pals G. Relative quantification of 40 nucleic acid sequences by multiplex ligation-dependent probe amplification. Nucleic Acids Res. 2002;30:e57.

Segert JA, Gisselbrecht SS, Bulyk ML. Transcriptional silencers: Driving gene expression with the brakes on. Trends Genet. 2021;37:514-27.

Sekido R, Lovell-Badge R. Sex determination involves synergistic action of SRY and SF1 on a specific Sox9 enhancer. Nature. 2008;453: $930-4$.

Sekido R, Bar I, Narváez V, Penny G, LovellBadge R. SOX9 is up-regulated by the transient expression of SRY specifically in Sertoli cell precursors. Dev Biol. 2004;274:271-9.

Shema E, Bernstein BE, Buenrostro JD. Single-cell and single-molecule epigenomics to uncover genome regulation at unprecedented resolution. Nat Genet. 2019;51:19-25.

Shi F, Ding S, Zhao S, Han M, Zhuang Y, Xu T, et al. A piggyBac insertion disrupts Foxl2 expression that mimics BPES syndrome in mice. Hum Mol Genet. 2014;23:3792-800.

Sinclair AH, Berta P, Palmer MS, Hawkins JR, Griffiths BL, Smith MJ, et al. A gene from the human sex-determining region encodes a protein with homology to a conserved DNAbinding motif. Nature. 1990;346:240-4.

Sock E, Schmidt K, Hermanns-Borgmeyer I, Bösl MR, Wegner M. Idiopathic weight reduction in mice deficient in the high-mobility-group transcription factor Sox8. Mol Cell Biol. 2001; 21:6951-9.

Sun D, Zhang Y, Wang C, Hua X, Zhang XA, Yan J. Sox9-related signaling controls zebrafish juvenile ovary-testis transformation. Cell Death Dis. 2013;4:e930.
Swain A, Narvaez V, Burgoyne P, Camerino G, Lovell-Badge R. Daxl antagonizes Sry action in mammalian sex determination. Nature. 1998;391:761-7.

Uda M, Ottolenghi C, Crisponi L, Garcia JE, Deiana $\mathrm{M}$, Kimber $\mathrm{W}$, et al. Foxl2 disruption causes mouse ovarian failure by pervasive blockage of follicle development. Hum Mol Genet. 2004;13:1171-81.

Uhlenhaut NH, Jakob S, Anlag K, Eisenberger T, Sekido R, Kress J, et al. Somatic sex reprogramming of adult ovaries to testes by FOXL2 ablation. Cell. 2009;139:1130-42.

Vainio S, Heikkilä M, Kispert A, Chin N, McMahon AP. Female development in mammals is regulated by Wnt-4 signalling. Nature. 1999; 397:405-9.

van Helden J. Regulatory sequence analysis tools. Nucleic Acids Res. 2003;31:3593-6.

Velagaleti GV, Bien-Willner GA, Northup JK, Lockhart LH, Hawkins JC, Jalal SM, et al. Position effects due to chromosome breakpoints that map approximately $900 \mathrm{~kb}$ upstream and approximately $1.3 \mathrm{Mb}$ downstream of SOX9 in two patients with campomelic dysplasia. Am J Hum Genet. 2005;76:652-62.

Verdin H, De Baere E. In: Adam MP, Ardinger HH, Pagon RA, Wallace SE, Bean LJH, Mirzaa GAA, editors. Blepharophimosis, Ptosis, and Epicanthus Inversus. GeneReviews [Internet]. Seattle: University of Washington; 1993

Verdin H, De Baere E. FOXL2 impairment in human disease. Horm Res Paediatr. 2012;77:211.

Vidal VP, Chaboissier MC, de Rooij DG, Schedl A. Sox9 induces testis development in XX transgenic mice. Nat Genet. 2001;28:216-7.

Wagner T, Wirth J, Meyer J, Zabel B, Held M, Zimmer J, et al. Autosomal sex reversal and campomelic dysplasia are caused by mutations in and around the SRY-related gene SOX9. Cell. 1994;79:1111-20.

Weider M, Wegner M. SoxE factors: Transcriptional regulators of neural differentiation and nervous system development. Semin Cell Dev Biol. 2017;63:35-42.
White MA, Kwasnieski JC, Myers CA, Shen SQ, Corbo JC, Cohen BA. A simple grammar defines activating and repressing cis-regulatory elements in photoreceptors. Cell Rep. 2016; 17:1247-54.

Wilhelm D, Martinson F, Bradford S, Wilson MJ, Combes AN, Beverdam A, et al. Sertoli cell differentiation is induced both cell-autonomously and through prostaglandin signaling during mammalian sex determination. Dev Biol. 2005;287:111-24.

Wilhelm D, Hiramatsu R, Mizusaki H, Widjaja L, Combes AN, Kanai Y, et al. SOX9 regulates prostaglandin $\mathrm{D}$ synthase gene transcription in vivo to ensure testis development. J Biol Chem. 2007;282:10553-60.

Wunderle VM, Critcher R, Hastie N, Goodfellow $\mathrm{PN}$, Schedl A. Deletion of long-range regulatory elements upstream of SOX9 causes campomelic dysplasia. Proc Natl Acad Sci U S A. 1998;95:10649-54.

Xiao B, Ji X, Xing Y, Chen YW, Tao J. A rare case of 46,XX SRY-negative male with approximately $74-\mathrm{kb}$ duplication in a region upstream of SOX9. Eur J Med Genet. 2013;56: 695-8.

Yamashita S, Kataoka K, Yamamoto H, Kato T, Hara S, Yamaguchi $\mathrm{K}$, et al. Comparative analysis demonstrates cell type-specific conservation of SOX9 targets between mouse and chicken. Sci Rep. 2019;9:12560.

Yang Y, Yang C, Zhu Y, Chen H, Zhao R, He X, et al. Intragenic and extragenic disruptions of FOXL2 mapped by whole genome low-coverage sequencing in two BPES families with chromosome reciprocal translocation. Genomics. 2014;104:170-6

Zhao L, Ng ET, Davidson TL, Longmuss E, Urschitz J, Elston M, et al. Structure-function analysis of mouse Sry reveals dual essential roles of the $\mathrm{C}$-terminal polyglutamine tract in sex determination. Proc Natl Acad Sci U S A. 2014;111:11768-73. 